$1: 15$

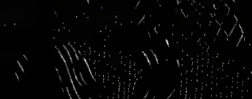

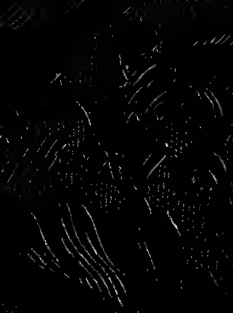

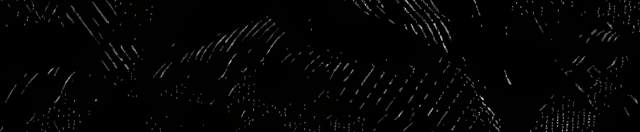

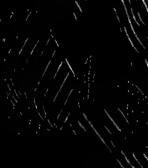

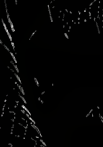

(1)

Wh

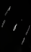

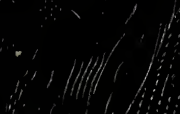

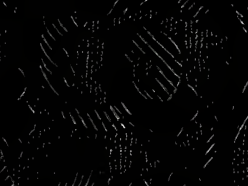

87

3. (1)ll, , isitis,

'3,

$(1 /, 1 / 1)$

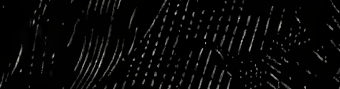

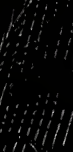

1/1/1/1/

$1 / 1, \quad \therefore l l l$, /1/1, $1 / 2$ A:

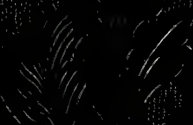
$\therefore \therefore(1 / 4)^{1 / 4}$ ind 7 sis 16 if

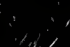
S / $/ 1$.

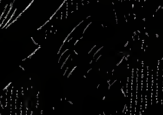
Niti Hath 
$8^{0}$

$$
4 x^{2}=107
$$





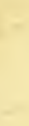

\section{$+$}


PI IV.
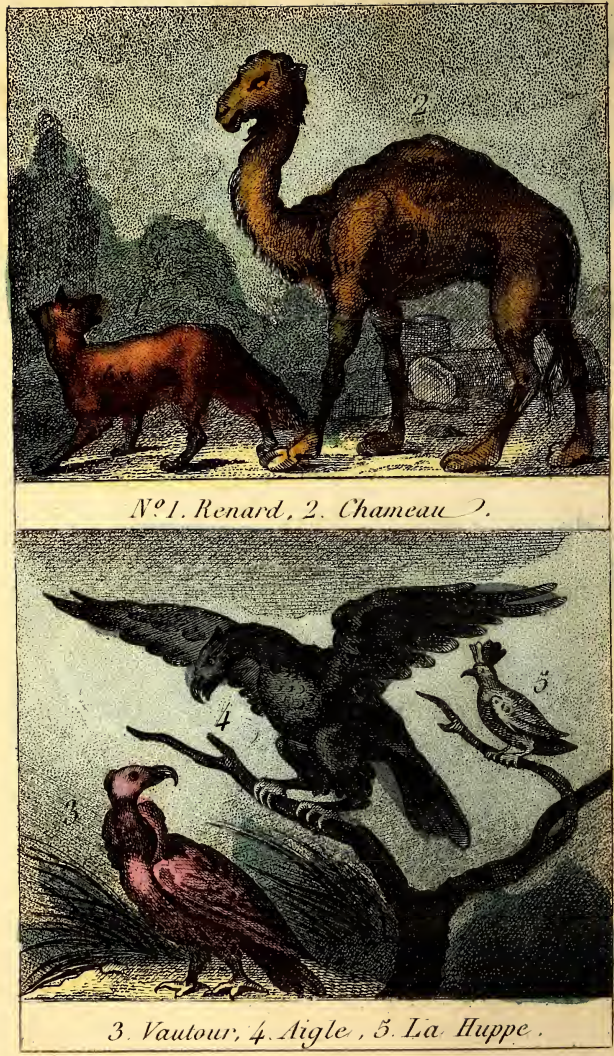


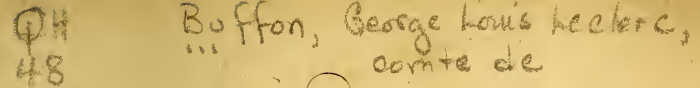

392

1847

Bifs

(3) DES ENFANTS

(cextratis at ov paxturelle

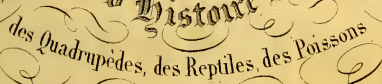

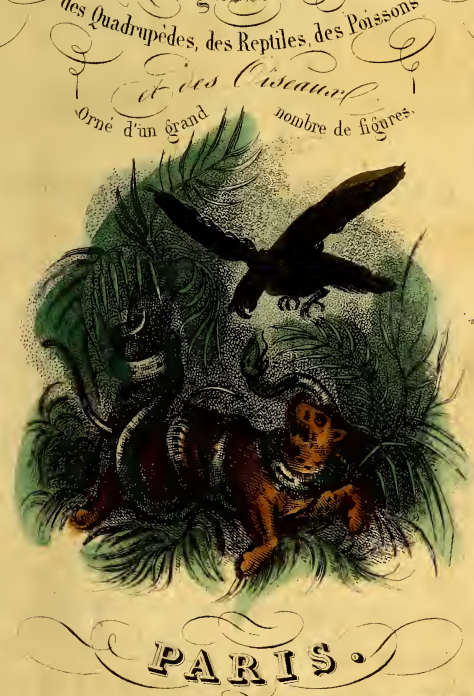

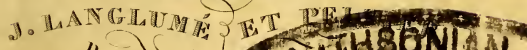

$$
\begin{array}{r}
\text { JUL } 221987 \\
\text { UIERARIES }
\end{array}
$$





\section{Le}
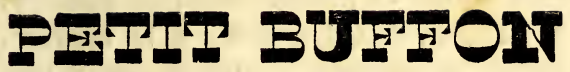

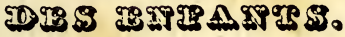

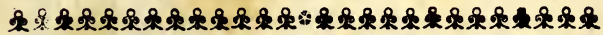

Des Quadrupèdes, des Reptiles. des Insectes et des Oiseaux.

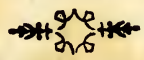

LE GHEVAL.

(Planche II, fig. 2.)

Le Cheval, ce fier et fougueux animal, partage avec l'homme les fatigues tie la guerre et la gloire des combats : aussi intrépide que son maître, il voit le péril et l'affronte; il se fait au bruit des armes, il l'aime, il le cherche et s'anime de la 
même ardeur : il partage aussi ses plaisirs ; à la chasse, aux tournois, à la course, il brille, il étincelle : mais docile autant que courageux, il ne se laisse point emporter à son feu, il sait réprimer ses mouvements; c'est une créature qui renonce à son être pour n'exister que par la volonté d'un autre, et qui, se livrant sans réserve, ne se refuse à rien, sert de toutes ses forces, s'excède, et même meurt pour mieux obéir.

Le naturel du cheval sauvage n'est point féroce ; il est fier, mais jamais il n'attaque, et s'il est attaqué, il dédaigne son ennemi, il l'écarte et l'écrase. Les chevaux sauvages vont par troupes; ils se réunissent pour le seul plaisir d'être ensemble; ils vivent en paix, parce que leurs appétits sont simples et modérés. Les - jeunes chevaux qu'on élève ensemble, et qu'on mène par troupeaux, ont les mours douces et les qualités sociales ; leur force et leur ardeur ne se marquent que par des signes d'émulation; ils cherchent à se devancer à la course, à se faire et même à 
DES ENFANTS.

s'animer au péril, en se défiant à travers une rivière, sauter un fossé; et ceux qui, dans ces exercices naturels, donnent l'exemple, sont les plus généreux, les meilleurs et souvent les plus dociles et les plus souples, lorsquils sont une fois domptés. Ceux qui l'ont déjà été, et qui se retrouvent en liberté dans les bois, ne deviennent pas sauvages une seconde fois; ils reconnaissent leurs maîtres et se laissent approcher et reprendre facilement. Le cheval se familiarise avec l'homme et s'attache à lui, il ne quitte point nos maisons pour se retirer dans les forêts; il marque au contraire beaucoup d'empressement pour revenir au gîte.

Voilà le cheval dont les talents sont développés, dont l'art a perfectionné les qualités naturelles, qui, dès le premier âge, a été soigné et ensuite exercé, dressé au service de l'homme. C'est par la perte de sa liberté que commence son éducation, et c'est par la contrainte qu'elle s'achève.

Les mœurs du cheval viennent donc presqu'entièrement de son éducation, et 
cette éducation suppose des soins et des peines que l'homme ne prend pour aucun autre animal, mais dont il est dédommagé par les services continuels que lui rend celui-ci.

Parmi les différentes races de chevaux, la plus estimée est celle des Arabes : les beaux chevaux de selle et de chasse nous viennent de Barbarie, d'Angleterre et du Limousin ; ceux de cavalerie, d'Espagne de Hongrie, du Danemarck et de plusieurs départements de France.

La durée de la vie des chevaux est, comme dans toutes les autres espèces d'animaux, proportionnée à la durée du temps de leur accroissement, qui se fait en quatre ans. Le cheval peut donc vivre six ou sept fois autant, c'est-à-dire vingt-cinq ou trente ans.

Après sa mort l'homme met à profit sa dépouille : les tamis, les archets d'instruments, les fauteuils, les coussins sont faits ou rembourrés avec son crin; les bourreliers, les cordonniers font grand usage de son cuir tanné. 


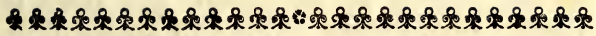

\section{L'ANE.}

(Planche VI, fig, 6.)

L'Ane de son naturel est aussi humble, aussi patient, aussi tranquille, que le cheval est fier, ardent, impétueux : il souffre avec constance et peut-être avec courage les châtiments et les coups : il est sobre et sur la qualité et sur la quantité de sa nourriture; il se contente des herbes les plus dures, les plus désagréables que les autres animaux lui laissent et dédaignent; il est fort délicat sur l'eau ; il ne veut boire que la plus claire et aux ruisseaux qui lui sont connus.

Comme on ne prend pas la peine de l'étriller, il se roule sur le gazon, sur les chardons et sur la fuugère, et sans se soucier beaucoup de ce qu'on lui fait porter, il se couche pour se rouler toutes les fois qu'il le peut, et semble reprocher par là à son maître le peu de soin qu'il|prend 
de lui; car il ne se vantre pas dans la fange et dans l'eau, il craint même de se mouiller les pieds, et se détourne pour éviter la boue; aussi a t-il la jambe plus sèche et plus nette que le cheval; il est susceptible d'éducation, et l'on en a vu d'assez bien dressés pour faire curiosité de spectacle. L'âne est peut être de tous les animaux celui qui, rélativement à son petit volume peut porter les plus grands poids; et comme il ne coûte presque rien à nourrir, et qu'il ne demande pour ainsi dire aucun soin, il est d'une grande utilité à la campagne, au moulin etc. Il peut aussi servir de monture, toutes ses allures sont douces et il bronche moins que le cheval; on le met souvent à la charrue dans les pays où le terrain est léger.

Si l'âne a de bonnes qualités il a aussi ses défauts, son cri ou braire est aussi désagréable que retentissant; quoique son caractère soit généralement doux et inoffensif, cet animal est capricieux et si têtu qu'on le tuerait plutôt que de lui faire faire ce qu'il s'est mis dans la tête de ne pas 
DES ENFANTS.

faire. Du reste, c'est à grand tort qu'on l'a accusé de stupidité, car son intelliggence surpasse celle du cheval. Il est très courageux, et se défend avec autant d'adresse que de fureur contre les autres animaux; et, si un loup est seul pour l'attaquer, l'âne vient aisément à bout de le mettre en fuite et même de le tuer.

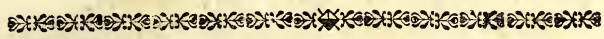

\section{LE CHIEN.}

- (Planche I, fig. 10.)

Outre la force, la vitesse et la légèreté , le Chien a par excellence toutes les qualités intérieures qui peuvent fixer les regards de l'homme. Son courage et son ardeur cédent au désir de plaire et an plaisir de s'attacher. Avant de faire usage de ses talents, il attend avec soumission le commandement de son maître.

Sans avoir, comme l'homme, la lumière de la pensée, il a toute la chaleur da sentiment et toute la pureté des affections. 
Plus sensible au souvenir des bienfaits qu'à celui des outrages, il ne se rebute pas par les mauvais traitements; et loin de s'irriter ou de fuir, il s'expose lui-même à de nouvelles épreuves, pour désarmer par la patience la main qui vient de le frapper.

Il fallait à l'homme ce compagnon fidèle, pour soumettre les animaux plus agiles et plus forts que lui, qui l'environnent.

Mille exemples prouvent l'attachement et la sagacité de cet animal. Un homme déguisé d'une manière ridicule, un jour de carnaval, fut mordu par son chien, qui d'abord ne le reconnut pas. Revenu de son erreur, le pauvre animal alla se cacher au fond d'un cellier où il mourut de douleur, quelques caresses que lui fil son maître pour le déterminer à revenir.

Le trait suivant est arrivé de nos jours. Un habitant de Valenciennes meurt, son chien suit le convoi et reste sur la tombe de son maître. Au bout de quinze jours, sa constance fit naître à des jeunes gens le projet de construire une cabane à ce gardien fidèle. Il y passa neuf ans, sans s'é- 
carter de plus de douze ou quinze pas du poste que son cœur lui avait assigné.

Dans les pays déserts, dans les contrées dépeuplées, il y a des chiens sauvages, qui, pour les mœurs, ne diffèrent des loups, que par la facilité qu'on trouve à les apprivoiser : ils se réunissent aussi en plus grandes troupes pour chasser et altaquer en force les sangliers, les taureaux sauvages et même les lions et les tigres. En Amérique, ces chiens sauvages sont de race anciennement domestique, ils y ont été transportés d'Europe; et quelques-uns ayant été abandonnés ou oubliés dans ces déserts, s'y sont multipliés au point qu'ils se répandent par troupes dans les contrées habitées, où ils attaquent le bétail et même les hommes; on est donc forcé de les écarter par la force, et ces chiens sont tels en effet tant qu'ils ne connaissent pas les hommes ; mais lorsqu'on les approche avec tranquillité, ils s'adoucissent, deviennent bientôt familliers, et demeurent aussi fidèlement attachés à leurs maîtres , que les chiens domestiques. 


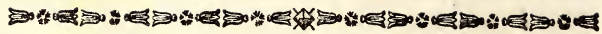

\section{LE LOUP.}

(Planche IX, fig. 4.)

De tous les temps, le loup a été le fléau des bergeries et la terreur des bergers; il est d'une constitution vigoureuse, il peut faire quarante lieues dans une seule nuit, et rester plusieurs jours sans manger. Sa force est supérieure à celle de nos chiens de plus grande race.

Si le loup n'est pas tourmenté par la faim, il se retire dans les bois, y passe le jour à dormir, et n'en sort que la nuit pour aller fureter dans la campagne. Alors il s'avance avec circonspection; sa marche est furtive et légère, il visite les collets tendus par les chasseurs, pour s'emparer du gibier qui peut s'y trouver pris ; il parcourt le bord des ruisseaux pour se nourrir des immondices que les eaux rejettent sur le sable; son odorat est d'une telle fi - 
DES ENFANTS.

nesse qu'il lui fait découvrir un cadavre à plus d'une lieue de distance. Dès que le jour approche, il regagne l'épaisseur du bois.

Mais quand cet animal est pressé par la faim, il oublie sa défiance naturelle et devient aussi audacieux qu'intrépide. Il sort alors du bois en plein jour. Il parcourt la campagne, s'approche des troupeaux et s'élance sans hésiter au milieu des chiens et des bergers, saisit un mouton, l'enlève et l'emporte avec une légèreté telle qu'il ne peut être atteint ni par les chiens, ni par les bergers.

D'autres fois, s'il a découvert un jeune chien inexpérimenté dans la cour d'une grange écartée, il s'en approche avec effronterie ; il prend alors différentes attitudes, fait des courbettes, des gambades, se roule sur le dos comme si son intention était de jouer avec le jeune novice. Quand celui-ci se laisse surprendre à ces trompeuses amorces, il est aussitôt étranglé et entraîné dans le bois voisin pour être dévoré. 
Le proverbe, les loups ne se mangent $p a s$, manque d'exactitude, car quand un loup blessé perd son sang, les loups voisins, souvent ses frères, attirés par l'odeur, le poursuivent, l'attaquent et le dévorent. Ces animaux sont en tout le symbole des méchants, qui après avoir fait la guerre aux bons et aux fuibles finissent par s'entre-détruire.

On en a vu suivre les armées, arriver en nombre à des champs de bataille où l'on n'avait enterré que négligemment les corps, les découvrir, les dévorer avec une insatiable avidité, et ces mêmes loups, accoutumés à la chair humaine, se jeter ensuite sur les hommes, attaquer le berger plutôt que le troupeau, dévorer des femmes, emporter des enfants, etc. L'on a appelé ces mauvais loups, loups garoux, c'est-à-dire loups dont il faut se garer.

Cet animal, quoique féroce, est timide : lorsqu'il tombe dans un piége, il est si fort et si long temps épouvanté , qu'on peut le tuer sans qu'il se défende, ou le prendre vivant sans qu'il résiste. 
DES ENFANTS.

Il n'y a de bon dans le loup que sa peau, dont on fait des fourures chaudes et durables. Désagréable en tout, la mine basse, la voix effrayante, l'odeur insupportable, le naturel pervers, les mœurs féroces, le loup est odieux, nuisible de son vivant, inutile après sa mort.

On en trouve en Europe, en Asie, en Afrique et même en Amérique; ils sont plus ou moins gros dans ces différentes contrées, et leur couleur ordinairement fauve, varie depuis le blanc jusqu'au noir. 


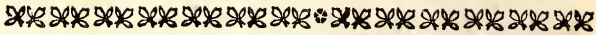

\section{LE GHAT.}

(Planche I, fig. 7.)

Le Chat est un animal domestique infidèle, qu'on ne garde que par nécessité, pour l'opposer à un ennemi domestique encore plns incommode et qu'on ne peut chasser. Quoique les chats, surtout quand ils sont jeunes aient de la gentillesse, ils ont en mème temps une malice innée, un caractère faux, un naturel pervers, que l'âge augmente encore, et que l'éducation ne fait que masquer. De voleurs déterminés, ils deviennent seulement, lorsqu'ils sont bien élevés, souples et flatteurs comme les fripons; ils ont la même adresse, la même subtilité, le même goût pour faire le mal, le même penchant à la rapine; comme eux ils sarent couvrir leur marche, dissimuler leur dessein, épier les occasions, attendre, choisir, saisir l'instant de faire leur coup, se dérober ensuite au 
DES ENFANTS.

châtiment. Ils prennent aisément des habitudes de société, mais ils n'ont que l'apparence de l'attachement; on le voit à leurs mouvements obliques, à leurs yeux équivoques; ils ne regardent jamais en face la personne aimée; soit défiance ou fausseté, ils prennent des détours pour en approcher, pour chercher des caresses auxquelles ils ne sont sensibles que pour le plaisir qu'elles leur font.

Les jeunes chats sont gais, vifs, jolis, et seraient très-propres à amuser les enfants, si les coups de pattes n'étaient pas à craindre; mais leur badinage, quoique toujours agréable et léger, n'est jamais innocent, et bientôt il se tourne en malice habituelle; et comme ils ne peuvent exercer leur naturel carnassier avec quelque avantage que sur les plus petits animaux, ils se mettent à l'affût près d'une cage; ils épient les oiseaux, les souris, les rats, et deviennent d'eux-mêmes, et sans y être dressés, plus habiles à la chasse que les chiens les mieux instruits. Leur naturel,ennemi de toute contrainte, les rend incapa- 
bles d'une éducation suivie; ils n'ont aucune docilité. On ne peut donc pas dire que les chats, quoiqu'habitants de nos maisons, soient des animaux domestiques; ceux qui sont les mieux apprivoisés, n'en sont pas plus asservis: on peut même avancer qu'ils sont entièrement libres; ils ne font que ce qu'ils veulent, rien ne pouvant les retenir dans un lieu d'où ils voudraient s'éloigner. D'ailleurs la plupart sont demi-sauvages, ne connaissent pas leurs maîtres, ne fréquentent que les greniers et les toits, et quelquefois la cuisine et l'office, lorsque la faim les presse. Leur sommeil est léger, et ils dorment moins qu'ils ne font semblant de dormir. Ils marchent légèrement, presque toujours en silence, dans l'espoir de saisir quelque proie.

Les lions, les tigres, les panthères et tous les animaux féroces à ongles retractiles, c'est-à-dire pouvant rentrer comme les ongles du chat lorsqu'il fait patte de velours, appartiennent à la famille du chat. 
DES ENFANTS.

0000000000000000000000000000

\section{IE RENARD.}

(Planche IV, fig. 1.)

Le Renard est fameux par ses ruses et mérite en partie sa réputation; ce que le loup ne fait que par force, le renard le fait par adresse et il réussit plus souvent. Sans chercher à combattre les chiens et les bergers, sans attaquer les troupeaux, sans traîner les cadavres, il est plus sûr de vivre: il emploie plus d'esprit que de inouvement; ses ressources semblent être en lui-même. Fin autant que circonspect, ingénieux et prudent même jusqu'à la patience, il varie sa conduite, il a des moyens de réserve qu'il sait n'employer qu'à propos. Il veille de près à sa conservation; quoiqu'aussi infatigable et même plus léger que le loup, il ne se fie pas entièrement à la vitesse de sa course, il sait se mettre en sûreté en se pratiquant un asile où il se retire dans les dangers pressants, où il s'établit, où il 
élève ses petits ; il n'est point animal vagabond, mais animal domicilié. Le renard tourne tout à son profit. Il se loge au bord des bois, à portée des hameaux; il écoute le chant des coqs et les cris des volailles, il les savoure de loin, il prend habituellement son temps, cache son dessein. et sa marche, se glisse, se traîne, arrive et fait rarement des tantatives inutiles. S'il peut franchir les clôtures et passer par-dessus, il ne perd pas un instant, ravage les basses cours, il y mel tout à mort, se retire ensuite lestement, en emportant sa proie qu'il cache sous la mousse, ou porte à son terrier ; il revient quelques moments après en chercher un autre qu'il emporte et cache de même; mais dans un autre endroit ; ensuite un troisième, un qua trième, etc., jusqu'à ce que le jour ou le mouvement dans la maison l'avertissent qu'il faut se retirer et ne plus revenir. It fait la même manœuvre dans les pipées et dans les boqueteaux où l'on prend les grives et les bécasses au lacet ; il devance le pipeur, va de très grand matin, et souvent 


\section{DES ENFANTS.}

plus d'une fois par jour, visite $r$ les lacets, les gluaux, emporte successivement les oiseaux qui se sont empétrés, les dépose tous en différents endroits, surtout au bord des chemins, dans les ornières, sous de la mousse, sous un génièvre, les y laisse quelquefois deux ou trois jours, et sait parfaitement les retrouver au besoin. II chasse les jeunes levreaux en plaine, saisit quelquefois les lièvres au gîte, ne les manque jamais lorsqu'ils sont blessés, déterre les lapereaux dans les garennes, découvre les nids des perdrix, des cailles, prend la mère sur les œufs, et détruit une quantité prodigieuse de gibier.

Le renard ne s'apprivoise pas aisément, jamais tout-à-fait ; il languit lorsqu'il n'a pas la liberté , et meurt d'ennui lorsqu'on veut le garder trop longtemps en domesticité.

Des renards qui se jetaient sur les poules lorsqu'ils étaient en liberté , n'y touchaient plus dès qu'ils avaient leur chaîne. On attachait souvent auprès d'eux une poule vivante, on les laissait passer la nuit en- 
20

LE BUFFON

semble, on les faisait même jeuner auparavant; malgré le besoin et la commodité, ils n'oubliaient pas qu'ils étaient enchaînés et ne touchaient point à la poule.

Le pelage du renard est ordinairement de couleur rousse, avec la gorge mêlée de blanc et de noir ; mais on connaît dans le Nord, le renard blanc, le noir, le bleu, le gris de toutes nuances, le blanc à pieds fauves, le blanc à tête noire, etc. Sa longueur moyenne est de quarante centimètres. 


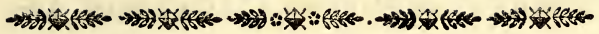

\section{L'ÉGUREUIL.}

(Planche I, fig. 12.)

L'Écureuil est un joli petit animal, propre, leste , vif , très alerte, très éveillé, très industrieux; il a les yeux pleins de feu : il n'est ni carnassier, ni nuisible; et quoiqu'il saisisse quelquefois les petits oiseaux qui se trouvent à sa portée, il ne vit pas communément de chair. La noisette, le gland, la faine et autres fruits sauvages, sunt sa nourriture ordinaire. Aussi propre qu'il est agile, il se fait un ornement de sa large queue qu'il relève sur son corps et sur sa tête en forme de panache.

Toujours en l'air, il ressemble aux oiseaux par sa légèreté. Au moyen de ses ongles qui sont très-aigus, il grimpe sur l'écorce la plus lisse, et parcourt les forêts, en sautant lestement d'un arbre sur l'autre. Comme il n'est qu'à demi sauvage,il semble 
aussi n'ètre quadrupède (1) qu'à demi. Assis sur les pieds de derrière et presque debout, il se sert de ceux de devant comme de mains pour porter à sa bouche.

Un petit grognement d'un ton aigu, est le signe de son mécontentement.

L'écureuil semble craindre le soleil, et ne quitte sa demeure que vers le soir, pour prendre de la nourriture ou pour jouer. Il construit son nid sur l'enfourchure d'une branche dans les plus hautes futaies, et lui donne assez d'espace et de solidité pour s'y loger avec sa famille à naître. La femelle met bas au printemps trois ou quatre petits. Ces animaux ont toujours le soin lorsqu'ils aperçoivent un chasseur, de se tenir derrière le tronc de l'arbre, et de tourner autour pour rester masqués, à mesure que le chasseur tourne lui mêmeautour de l'arbre. Ils n'en continuent pas moins à monter ; et, parvenus à l'enfourchure d'une branche, ils s'y blotissent et restent invisibles.

(1) Quadrupède, animal à quatre pieds. 
DES ENFANTS.

L'écureuil est beaucoup plus nombreux dans le Nord que dans tout autre climat. On fait des pinceaux avec le poil de sa queue.

\section{LE CHAMOIS.}

(Planche VII, fig. 4.)

Le Chamois, que l'on nomme aussi Ysard, est plus grand que la chèvre, et ressenble beaucoup au cerf pour la forme du corps. De chaque côté de la face sont deux bandes de poil noir qui tranchent sur un fauve blanchâtre. Cet animal porte en hiver une double fourrure, comme presque tous les animaux du Nord, et sa couleur varie suivant la saison, depuis le gris cendré jusqu'au brun noirâtre. Le mâle et la femelle ont des cornes longues de six ou neuf pouces, placées fort en avant, droites jusqu'à une certaine hauteur, et courbées en arrière à la pointe. Ces cornes 
ne tombent jamais; elles croissent chaque année d'un anneau, comme il arrive à tous les animaux de l'espèce des chèvres.

Le chamois habite les montagnes les plus escarpées : ses jambes longues et nerveuses lui donnent la facilité de franchir les précipices, et de s'élancer avec une extrème légèreté de rochers en rochers, par-dessus des abîmes profonds. Sa voix est un bèlement qui approche de celui d'une chèvre enrouée; mais lorsqu'il est surpris et effrayé, il fait entendre un sifflement très aigu. Il se nourrit de fleurs, de bourgeons tendres des arbrisseaux, et surtout des plantes les p'us aromatiques.

Le chamois se plaît sur les plus hautes montagnes. On ne le trouve guère en France que sur les Alpes et les Pyrénées. Leur chasse est très dangereuse, et beaucoup de chasseurs de chamois périssent en tombant dans les précipices.

La peau tannée du chamois sert a faire des gants solides et estimés. 
$2626262626262,626262,62,62152$

\section{LA GHAUVE-SOURIS.}

(Planche VII, fig. 3.)

La Chauve-Souris n'a de commun avec les oiseaux, que la faculté de voler. Ses ailes ne sont autre chose que de larges membres, qui séparent les ongles prolongés des pattes de devant. Les moucherons, les cousins, et surtout les papillons de nuit lui servent de nourriture.

I a femelle fait, en été, un ou deux petits qu'elle allaite et qu'elle transporte en vo lant.

Aux approches de l'hiver, les chauvesouris se retirent dans des cavernes, dans des réduits sombres et chauds, où elles restent jusqu'au printemps dans un engourdissement dont la cause est leur peu de chaleur intérieure. Les unes s'accrochent par les pieds à la voûte de leur domicile, et restent ainsi suspendues la têt en bas, et couvertes de leurs ailes 
comme d'un manteau; les autres se collent contre les murailles, ou s'enfoncent dans des trous.

On distingue plusieurs espèces de chauve-souris. La plus remarquable est l'oreillard, ainsi nommée à cause de la grandeur démesurée de ses oreilles. Et le vampire de la Guyane qui est de la grosseur d'un fort pigeon.

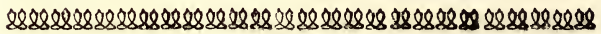

\section{LA SOURIS.}

Si la Souris n'était pas aussi nuisible, son air vif et ses mours douces nous la feraient trouver agréable. Son instinct est le même que celui du rat ; mais à la moindre alerte, elle rentre dans son trou, au lieu que le rat tient quelquefois ferme, et n'est pas toujours attaqué impunément. Sa petitesse et son agilité sont les seules ressources qu'elle ait contre les nombreux ennemis qui la guettent et la poursuivent continuellement. 
Les souris produisent plusieurs fois l'année, et dans toutes saisuns. Leurs petits, au nombre de cinq à six à chaque portée, sont assez forts au bout de quinze jours, pour se disperser, et aller chercher de quoi vivre.

Un si prompt accroissement prouve que leur vie n'est pas de longue durée.

Ce petit animal suit ordinairement l'homme, parce qu'il se nourrit des aliments que l'homme prépare. Il est naturel à l'Europe, à l'Asie et à l'Afrique ; mais on prétend qu'il n'existait point en Amérique. 


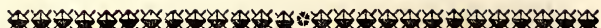

\section{LE RAT.}

(Planche I, fig. 13.)

Cet animal incommode se nourrit de grains , fruits, chairs , laine, étoffes , meubles : tout est de son goût; il perce même le bois et les murs pour s'y nicher et y faire son magasin. Sa fécondité est extrême. Il produit plusieurs fois par an , et toujours en grand nombre. La mère défend ses petits avec courage ; en se bat. tant contre les chats, à moins qu'ils ne soient vigoureux et aguerris.

Si quelquefois on voit une multitude de rats disparaître tout-à-coup, c'est que, la disette les obligeant à se détruire, ils se font une guerre cruelle qui ne finit que par l'extinction presque totale des individus. La lettre suivante, écrite en 1757 , par un officier de marine, observateur judicieux, prouve que ces animaux, 
malgré leur cruauté , sont quelquefois des modèles de tendresse filiale.

" J'étais ce matin dans mon lit, occupé à lire , j'ai été interrompu par un bruit semblable à celui que font les rats qui grimpent contre une closion. J'ai observé attentivement, j'ai vu parâitre un rat sur le bord d'un trou, il a regardé de tous côtés, et ensuite s'est retiré , un moment après il a reparu : il conduisait par l'oreille un rat plus gros que lui et qui paraissait vieux. L'ayant laissé sur le bord du trou, un autre jeune rat s'est joint à lui ; ils ont tous deux parcouru la chambre en ramassant les mieltes de biscuit qui étaient tombées de la table au souper de la veille : ils les ont portées à celui qui était sur le bord du trou. Cette attention m'a étonné. J'ai observé encore avec plus de soin. J'ai jugé que le rat auquel les deux autres portaient à manger, était aveugle, parce qu'il ne trouvait qu'en tâtonnant le biscuit qu'on lui présentait. Je n'ai point de doute que les deux jeunes ne fussent les pourvoyeurs assidus d'un 
père affligé... Tandis que j’admirais la nature, et que je faisais des réflexions, on a ouvert la porte de ma chambre. Les deux jeunes rats ont fait un cri comme pour avertir l'aveugle et malgré leur frayeur, ils n'ont voulu se sauver que quand le vieux a été en sûreté."

Le rat est originaire d'Amérique. L'espèce du rat noir la seule connue il y a cent ans a presque totalement disparu. Elle a été remplacée par le surmulot venu de l'Inde; plus furt et plus féroce que le rat noir, il lui a fait la guerre, en a détruit la race et l'a remplacée. Ainsi le rat ordinaire, le rat gris enfin et ce que les naturalistes appellent le surmulot. 


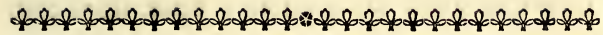

\section{LE HÉRISSON.}

(Planche I, fig. 14.)

Le Hérisson est un animal innocent et paisible, qui ne fait usage de ses armes que contre ses ennemis. Lorsqu'on l'attaque, il se roule en boule, et présente de tous côtés les pointes dont il est hérissé. C'est là son unique défense, car il ne sait ni fuir ni combattre. Pour l'obliger à s'étendre, on le plonge dans l'eau.

Loin de nuire dans un jardin, il y mange les vers et les autres insectes. Il se tient ou au pied des arbres, dans la mousse, ou sous des monceaux de pierre. On ne le voit pas de tout le jour, mais il marche la nuit. Son engourdissement pendant l'hiver a la même cause que celui de la chauve-souris.

Cet animal a les yeux petits, les oreilles larges et courtes. On remarque entre 
32

ses épines quelques poils rudes de la nature des soies de cochon : ceux dont son ventre est couvert, sont plus doux, rares et crépus. Sa peau servait autrefois de vergette et de frottoir, ou de peigne pour sérancer le chanvre. La femelle produit, au commencement de l'été, quatre ou cinq petits, sur lesquels on ne voit encore que la naissance des épines. Leur couleur blanche se change à mesure qu'ils croissent, en un gris sale et foncé.

Le hérisson est assez généralement répandu, excepté dans les pays les plus froids. 
Pl.l.

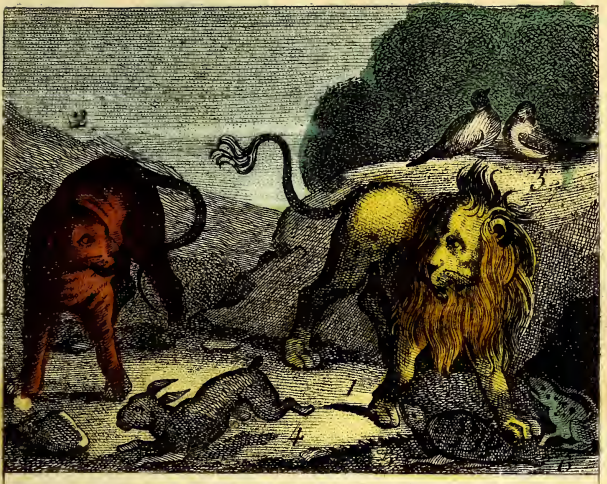

D?1. Lion, 2. Tugro, 3 Pigeons, 4. Lapin, 5.Tortue, 6. Grenouille.

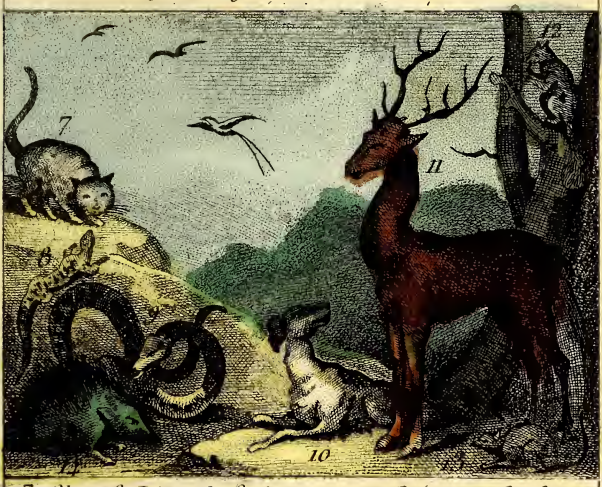

7. that, 8 Lievard, 9. Serpent, 10. Chicn, II. Cerf,12. ticuiveuil, 13 Rat, 14 . Tie llérisson. 



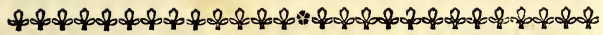

\section{LE LION.}

( Planche I, fig. 1.)

Le Lion est le plus fort et le plus terrible des animaux. Il a la tête grosse et charnue, le nez long, large et ouvert, le front carré, et comme sillonné de rides profondes, surtout lorsqu'il est en fureur, les yeux vifs et perçants, et les sourcils épais. Chacune de ses mâchoires est garnie de quatorze dents, et sa langue est couverte de pointes aussi dures que de la corne.

Une longue et rude crinière, qui devient plus belle avec l'âge, ombrage sa tête et son cou. Il a les jambes courtes et usseuse, les pieds gros et larges. Ceux de devant sont divisés en cinq griffes bien articulées; ceux de derrière en quatre toutes armées d'ongles forts et pointus. Sa queue, longue d'environ quatre pieds, est 
extrêmement souple et couverte d'un poil court jusqu'à l'extrémité, qui se termine en touffe. L'animal s'en sert pour terrasser et briser l'ennemi qu'il veut étreindre.

Le rugissement est la voix ordinaire du lion. Il est effrayant. C'est une espèce de grondement d'un ton ggrave, mêlé d'un frémissement aigu; mais le cri qui exprime sa colère, est plus terrible encore. Ce cri est court et réitéré subitement. Alors il se bat les flancs avec sa queue, il en frappe la terre, dresse sa crinière, et montre ses dents menaçantes et sa langue armée de pointes. Aussitôt il saute sur sa proie, fait un bond de douze ou quinze pieds, tombe dessus, la saisit avec ses pattes de devant, la déchire avec les ongles et ensuite la dévore avec ses dents.

Sa plus grande taille est d'environ trois mètres de longueur sur un et demi de hauteur. La femelle, plus petite dans toutes ses dimensions, ne porte point de crinière. Ses traits moins prononcés, ou plutôt radoucis, indiquent des inclinations plus douces. Sa force est 
DES ENFANTS.

dans l'amour maternel. Dès qu'elle a des petits elle ne connaît point le danger ; elle se jette indifféremment sur les hommes et sur les animaux, quel que soit leur nombre.

Le moyen de se débarrasser d'une lionne, lorsqu'on est surpris à lui enlever ses lionceaux, est de lui en abandonner un, qu'elle court aussitôt porter à sa caverne.

Le lion n'attaque que par nécessité. Sa voracité finit où ses besoins cessent. 0 n connaît ses différentes affections aux mouvements de sa queue. Si la faim le presse, il tombe indifféremment sur tout ce qui se présente, et la résistance ne fait qu'augmenter sa rage; aussi est-il fort dangereux de le blesser sans l'abattre.

Il arrive assez souvent aux peuples de l'Asie et de l'Afrique, où les lions se trouvent en abondance, de rencontrer de ces animaux dans leurs chasses. Alors leurs chevaux, quoique très-vifs, sont saisis d'une terreur si subite, qu'ils deviennent immobiles, et les chiens se tien- 
nent rampanis auprès de leurs mal̂́res. Le meilleur expédient pour le cavalier, est de descendre, et d'abandonner une proie qu'il ne peut défendre. Si, par une rencontre imprévue, on se trouvait trop près et qu'on n'eût pas le temps d'allumer du feu pour effrayer cet animal, l'unique parti à prendre serait de se coucher par terre dans un profond silence. Lorsque le lion n'est pas tourmenté par la faim, il passe gravement, comme s'il était satisfait des marques de respect qu'on lui donne. Les nègres creusent, pour prendre les lions, de grandes fosses qu'ils couvrent de branches et de feuillages, et sur lesquels ils mettent une pièce de chair pour amorce.

La durée de la vie du lion est d'environ vingt-cinq ans. Sa nourriture dans les forêts, sonı les gazelles el les singes. Il les attend plus souvent qu'il ne les poursuit, quoique son agilité soit égale à sa force. Un bon repas lui suffit pour trois jours; mais il boil toutes les fois qu'il trouve de l'eau. La lionne met bas au printemps, et ne produit qu'une fois l'année. 
Le lion pris jeune peut s'apprivoiser et même s'attacher à ceux qui le soignent. A quelque extrémité qu'il soit réduit, il est rare qu'il tourne sa colère contre son bien. faiteur ; mais il conserve longlemps le souvenir des iujures, et paraît en méditer la vengeance. L'histoire nous parle de lions conduits à la guerre ou menés à la chasse, et qui, fidèle à leur maître, ne déployaient leur force et leur courage que contre ses ennenis. A Rome on en vit d'altelés à des chars. Parmi une foule d'exemples frappants, nous choisirons celui de la lionne du fort Saiat-Louis, en Afrique.

Cne belle lionne que l’on gardait enchıînée pour l'envoyer $\boldsymbol{c}$. France, fut alteinte d'un mal violent à la $m$ âchoire, qui la priva de la faculté de manger : comme on désespérail de sa guérison, on lui ôta sa chaine et on jeta le corps dans un champ voisin. Ses yeux étaient fermés, et sa gueule ouverte était déjà remplie de fourmis, lorsqu'un Français, nommé Compagnon, l'aperçut en revenant de la chasse. Compagnon croyant trouver quelque, reste de vie daus 
ce pauvre animal, lui lava le gosier avec de l'eau, el lui fit avaler un peu de lait. Un remède si simple eut des effets merveil. leux. La lionne fut rapportée au fort : on en prit tant de soins, qu'elle se rétablit par degrés. N'oubliant jamais à qui elle était redevable d'un si grand service, elle conçut une telle affection pour son bienfaiteur, qu'elle ne voulut rien prendre que de sa main ; et lorsqu'elle fut tout-à-fait guérie, elle le suivait dans lîle, avec un cordon au cou, comme le chien le plus familier. Tel est le pouvoir des bienfaits sur les caractères même les plus farouches.

Parmi les lionnes qui ont vêcu récemment à la ménagerie, plusieurs ont souffert des chiens dans leur loge; mais une seule a montré de l'amilié pour son camarade de prisun. Elle se nommait Constantine, et avait éié prise fort jeune dans le Sahara. On jeta dans sa loge un petit roquet noir et blanc, qui, tout efrrayé, fut se cacher dans un coin, en tremblant de tous ses membres. La lionne se leva lentement ; et, râlant d'unc voix sourde, s'ap- 
procha du pauvre animal, qui poussa un cri plaintif, en la regardant d'un air suppliant. Il paraît que ce regard plein de désespoir la toucha, car elle se recoucha tranquillement sans faire de mal au roquet. L'heure de la distribution étant venue, on jeta dans la loge le dîner de Constantine; elle le mangea, et en laissa une part pour son nouveau compagnon d'esclavage, qui n'osa pas y toucher, car la faim la plus dévorante n'aurait pu le déterminer à quitter le coin noir où la frayeur le tenait blotti. Le lendemain, il avait un peu moins peur, et il se détermina à manger la portion, que la lionne lui laissa comme la veille; huit jours après, il mangeait avec elle, et huit jours après, il se jettait sur le dìner, et ne permettait à la lionne d'en avoir sa part, que lorsqu'il avait pris la sienne. Si Constantine approchait, le roquet entrait en fureur, et purement par caprice, lui sautait à la figure, et la mordait de toute sa force.

Quand l'automne fut venue avec ses journées froides et humides, le roquet, 
pour être plus chaudement, jugea à propos de passer la nuit entre les cuisses de la lionne, et elle s'y prêta de fort bonne grâce. Pour récompense, dans ses accès de fureur, il se jeta un jour sur elle, et lui mordit la queue avec tant de rage et de méchanceté, qu’il parvint à la lui couper à moitié, et à l'estropier pour toute sa vie. Au bout de quelques années, le chien mourut, moitié de vieillesse, moitié d'un accès de colère, et la pauvre Constantine ne put jamais s'en consoler. On lui donna plusieurs autres chiens qu'elle étrangla; enfin elle laissa la vie à l'un d'eux, mais jamais elle ne lui montra ni affection ni complaisance, et elle mourut bientôt après, consumée d'ennui, de tristesse el de regrets. 


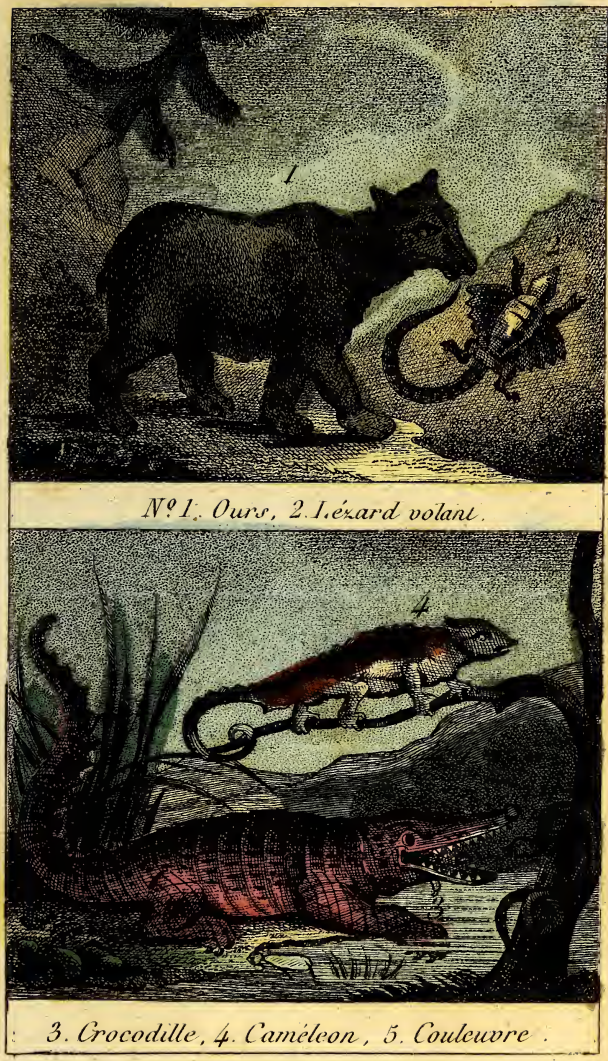





\section{L'OURS.}

(Planche V, fig. 1.)

L'Ours est non-seulement sauvage , mais solitaire; il fuit par instinct toute société, il s'éloigne des lieux où les hommes ont accès, il ne se trouve à son aise que dans les endroits qui appartiennent encore à la vieille nature : une caverne antique dans des rochers inaccessibles; une grotte formée par le temps dans le tronc d'un vieux arbre, au milieu d'une épaisse forêt, lui servent de domicile; il s'y relire seul, y passe une partie de l'hiver sans provisions, sans en sortir pendant plusieurs semaines. Cependant il n'est point engourdi ni privé de sentiment, comme le loir et la marmotte, mais comme il est naturellement gras, et qu'il l'est excessivement sur la fin de l'automne, temps auquel il se recèle, cette 
abondance de graisse lui fait supporter l'abstinence, et il ne sort de sa bauge que ıorsqu'il est affamé.

Les mâles des ours bruns dévorent les oursons nouveaux-nés, mais les femelles semblent les aimer jusqu'à la fureur ; elles sont lorsqu'elles ont mis bas, plus féroces, plus dan ̧ereuses que les mâles ; elles combattent et s'exposent à tout pour sauver leurs petits. Elle en a le plus grand soin, elle leur prépare un lit de mousse et d'herbes dans le fond de sa caverne, et les allaite jusqu'à ce qu'ils puissent sortir avec elle. Le mâle et la femelle n'habitent point ensemble, ils ont chacun leur retraite séparée et même fort éloignée; lorsqu'ils ne peuvent trouver une grotte pour se gîter, ils cassent et ramassent du bois pour se faire une loge qu'ils recouvrent d'herbes et ${ }_{2}^{?}$ de feuilles, au point de la rendre impénétrable à l'eau.

L'ours est très-susceptible de colère, et sa colère tient toujours de la fureur et souvent du caprice; quoiqu'il paraisse doux pour son maître , et même obéissant lors- 
qu'il est apprivoisé, il faut toujours s'en défier et le traiter avec circonspection. On lui apprend à se tenir de bout, à gesticulier, à danser ; il semble même écouter le son des instruments, et suivre grossièrement la mesure; mais pour lui donner celte espèce d'éducation, il faut le prendre jeune et le contraindre pendant toute sa vie; l'our's qui a de l'âge ne s'apprivoise ni ne se contraint plus. Il est naturellement intrépide, ou tout au moins indifférent au danger. L'ours sauvage ne se détourne pas de son chemin et ne fuit pas à l'aspect de l'homme; cependant lorsqu'on l'offense, ou lorsqu'on l'irrite sa colère est extraordinaire. Malheur au chasseur imprudent qui l'attaque sans être sûr de lui donner la mort du premier coup ! Car alors il est terrible.Sans hésiter, il court sur son agresseur ; mugissant de fureur , l'œil en feu, la gueule béante, dressé sur ses pieds de derrière il s'élance, l'écrase de son poids, le saisil dans ses bras puissants, l'étouffe ou lui brise le crâne avec ses furmidables machoires. 
Dans les contrées du nord où cet animal est très commun on le chasse pour sa graisse et sa peau. Car de toutes les fourrures grossières, la peau de l'ours est celle qui a le plus de prix.

On connaîı trois espèces d'ours. L'ours brun ou roux est carnassier et féroce. On le trouve dans tous les climats de l'ancien continent. L'ours noir, qui est le plus grand de tous, n'est que farouche et refuse de manger de la chair. L'ours blanc qui habite les bords de la mer glacial. Il se nourrit habituellement de poisson, cependant il est d'une grande férocité. 


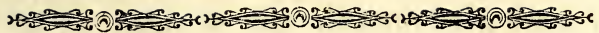

\section{LE TIGR.}

(Planche I, ffg. 2. )

Le Tigre est la plus grande et la plus terrible espèce de son genre : il égale et surpasse même le lion en grandeur, mais il est plus grêle ; sa tête esı plus ronde, ses jambes sont plus longues.

Il est plus sanguinaire que le lion, car il tue pour le plaisir de verser le sang. Mais il met plus de ruse pour s'approcher de sa proie et plus d'audace pour la vaincre.

Le tigre attaque sa proie en plein jour. On l'a vu sortir de la forêt, saisir un cavalier au milieu d'un bataillon; d'une armée, l'emporter dans les bois et disparaître avec, avant qu'on ait pu le poursuivre.

Heureusement l'espèce du tigre n'est pas nombreuse; elle est confinée dans les parties les plus brûlantes de l'Afrique et de l'Asie. La femelle produit, comme la

$$
3^{*}
$$


lionne, quatre ou cinq petits : elle est alors encore plus furieuse que le mâle, et sa rage n'a point de bornes lorsqu'on les lui ravit.

Le naturel du tigre est indomptable. Dans la captivité, il déchire la main qui le nourrit, comme celle qui le frappe. Son rugissement est sourd et comme engouffré. On peut s'en former une idée par le grondement du chat, lorsqu'il tient sa proie. Tous ses mouvements sont vifs et agiles. Sa peau marquée de larges bandes noires sur un fond fauve, qui commencent sur le dos et se rejoignent sous le ventre, offre un coup d'œil agréable. Son poil est doux et luisant; celui qui couvre sa longue queue est fort court. Ses jambes sont courtes, mais souples et fortes. Il peut comme le chat retirer et cacher les ongles dont ses pieds sont armés.

Les tigres de la grande espèce, ont quelquefois jusqu'à trois mètres de longueur, sans y comprendre la queue. Ils sont si forts, que quand ils ont mis à mort quelque gros animal, comme un buffle, 
DES ENFANTS.

un cheval, ils l'emportent avec tant de vitesse, que leur course n'en paraît pas ralentie.

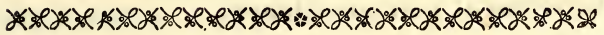

\section{LA PANTHÈrE.}

( Planche III , fig. 3.)

La Panthère ressemble, pour la tournure, à un dogue de forte race, excepté qu'elle est plus basse des jambes. Elle a le regard cruel, les mouvements brusques et l'air inquiet. Sa langue est rude, et ses mâchoires sont armées de dents fortes et aiguës. Sa peau fauve sur le dos et blanchâtre sous le ventre, est parsemée de grandes taches noires circulaires ou ovales, bien séparées les unes des autres. Ces taches sont pleines sur la tête, la poitrine, le ventre, les jambes et la base de la queue: sur le dos elles sont évidées dans leur milieu, ou remplies d'une ou de plusieurs petiles marques noires, qui 
en occupent le centre. La queue longue d'environ quatre-vingt centimètres, est couverte à son extrémité, d'anneaux alternativement noirs et blancs.

Cet animal ne se trouve que dans les cuntrées les plus chaudes de l'Asie et de l'Afrique. Il habite les forêts touffues et s'approche des habitations isolées pour surprendre les animaux; mais rarement il attaque l'homme. Malgré sa férocité, on le domple et on le dresse pour la chasse. 


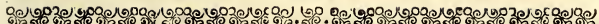
कम

\section{LE LEOPARD.}

(Planche III, lig. 2.)

Le Léopard tient le milieu pour la grandeur, entre l'once et la panthère, ayant à peu près 1 mètre 30 centimètres de longueur, et sa queue 80 centimètres. Quoiqu'il soit sujet à varier pour les couleurs, on peut dire en général, qu'il est d'un fauve plus ou moins foncé, avec le ventre blanchâtre : ses taches sont en cercle, comme celles de la panthère, mais plus petites, plus irrégulières, et assez communément formées de cinq ou six petites taches pleines.

Cet animal célèbre par son courage et sa cruauté attaque indifféremment les homnes et les animaux, et désole le pays qu'il habite. Il ne paraît pas qu'on ait jamais pu le dompter ni le dresser pour la chasse. Son regard est cruel, et ses yeux sont dans un mutvement continuel. Il a les dents très fortes et les ongles aigus et 
tranchants. On le trouve dans les mêmes contrées que le tigre et la panthère.

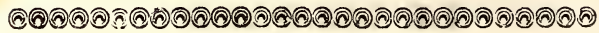

\section{LE LYNX.}

(Planche VII , fig. 5. )

Le Lynx, que l'on nomme aussi loupcervier, parce que son hurlement approche de celui du loup, et qu'il est marqué de taches qui ressemblent à celles des jeunes cerfs, a la forme et les habitudes du chat. Il se trouve dans les parties septentrionales de l'un et de l'autre continent. Sa couleur est d'un jaune fauve clair, avec des taches noirâtres, mal terminées, mais mieux marquées dans le mâle que dans la femelle. Il a la taille du renard, la queue très courte, le poil long et doux, les oreilles grandes, avec un pinceau de poils noirs à l'extrémité, et l'œil si perçant qu'on le cite comme proverbe. Cet animal se tient sur les arbres, donne la chasse aux écureuils, aux chats sauvages, aux mar- 
DES ENFANTS.

tres, aux oiseaux, et se précipite sur le chevreuil, le lièvre et les autres animaux qui passent à sa portée.

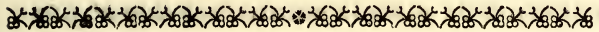

\section{L'ÉLÉPHANT.}

(Planche II, fig. 5.)

L'éléphant surpasse en grosseur tous les quadrupèdes connus. Sa tête est monstrueuse, ses oreilles sont longues, larges et épaisses. Ses yeux quoique grands, paraissent petits, proportionnellement au reste du corps, mais ils sont vifs et spirituels. Son nez qu'on appelle trompe, est une espèce de tuyau flexible en tous les sens, et assez long pour toucher à terre . C'est avec le rebord de cette trompe, qui forme comme un doigt, qu'il peut saisir les choses les plus petites, dénouer des cordes, déboucher une bouteille, etc. ; faire en un mot tout ce qu'on fait avec la main. Ce même instrument, lui sert à embrasser de grosses bottes d'herbes et à les élever 
jusqu'à sa bouche, pour boire, il s'en sert comme d'une pompe. Il n'a dans chaque mâchoire que quatre dents pour broyer sa nourriture ; mais la nature lui a donné pour sa défense deux autres dents, en forme de crochets, qui sortent de la mâchoire supérieure, et qui sont longues de plusieurs pieds. Ce sont ces dents que les artistes emploient si avantageusement sous le nom d'ivoire. Une seule pèse quelquefois plus de cent livres : elles croissent avec l'âge. Un gros éléphant contient plus de chair que quatre ou cinq bœufs. Leur mesure ordinaire est de trois mètres de long sur quatre de hauteur. Celui qui mourut à la ménagerie de Versailles en 1681, était de la petite taille; cependant l'anatomiste qui le disséqua, entrait tout entier dans son corps, et y travaillait comme dans une chambre. Pour avoir une idée de la force de cet animal, il n'y a qu'à se figurer qu'il ébranle la terre sous ses pas, qu'avec sa trompe il arrache des arbres, que d'une secousse il fait brèche dans un mur, et qu'il peut porter sur son dos une tour 
DES ENFANTS.

armée en guerre, et chargée de combattants. Seul, il fait mouvoir des machines et transporte des fardeaux que six chevaux ne pourraient remuer. Quoiqu'il ait les jambes fort épaisses et les pieds monstrueux, son pas ordinaire égale celui de l'homme le plus agile; aussi fait-il quinze à vingt lieues par jour, et plus de trente quand on le presse. Celui qui le conduit lui fait comprendre ses volontés en le frappant derrière la tête, sur la partie de son crâne qui a le moins d'épaisseur.

La couleur ordinaire des éléphants est d'un gris noirâtre. Il y en a aussi de blancs. Leur peau dure et ridée, n'offre que quelques poils rudes, répandus par intervalles et sans aucune continuité. La houppe des filets solides et luisants qui terminent leur queue, leur sert à se délivrer des mouches.

Comme les éléphants privés ne multiplient point, on n'a pas de certitude sur la durée de leur vie : on soupçonne seulement qu'ils doivent aller à plus de cent cinquante ans. La femelle ne produit qu'un 


\section{4}

\section{LE BUFFON}

petit, qui tète, non pas par la trompe comme on l'avait cru, mais par la bouche, conıme tous les autres animaux.

L'espèce de l'éléphant est généralement répandue dans toutes les contrées méridionales de l'Afrique et de l'Asie. Dans l'état sauvage, il se nourrit d'herbes, de feuillages, de fruits, de graines et de jeunes pousses d'arbres. Quoiqu'il puisse passer plusieurs jours sans prendre d'aliments, lorsqu'il se trouve dans l'abondance, il mange prodigieusement. La nourriture de celui de la ménagerie, quoiqu'il soit de la petite espèce, consistait en quatrevingts livres de pain par jour; douze pintes de vin et deux sceaux de potage, où il entrait quatre ou cinq livres de pain, sans compter ce que lui jettent les personnes qui viennent le voir. Ces animaux ont plusieurs ennemis, tel que le lion, le tigre, le rhinocéros et certains serpents. Si l'on vient à les harceler dans un endroit où ils aient la liberté de se tourner, leur trompe est un instrument de vengeance terrible,et l'ennemi qu'ils saisissent ne peut 


\section{DES ENFANTS.}

éviter d'être écrasé ou mis en pièces. Pour les blesser mortellement, il faut les frapper entre les yeux et les oreilles ; ailleurs leur peau résiste aux balles du mousquet. La manière de les ṕrenulre mérite une attention particulière. Au milieu des forêts, et dans un lieu voisin de ceux qu'ils fréquentent, on choisit un espace qu'on environne d'une forte palissade, et on les y fait entrer en les épouvantant par des cris, des pétards, des tambours et des torches allumées. D'autres fois, on leur jette aux jambes des lacets de cordes très fortes, et lorsqu'on a rencontré un arbre assez gros pour y lier sûrement les cordes, on amène les éléphants privés, qui harcèlent les éléphants sauvages avec leur trompe, jusqu'à ce qu'ils se soient laissés conduire au lieu qu'on leur a destiné.

Les nègres d'Afrique, qui n'en veulent qu'à leur chair, les attrapent dans des fosses profondes, couvertes seulement d'un peu de terre et de branches.

L'éléphant est presque aussitôt apprivoisé que vaincu. Quinze jours suffisent 
pour lui apprendre tous les exercices qu'on demande de lui. Du reste, s'il est intelligent et docile, il exige de son maître de la douceur et de bons traitements.

On dit que celui qui mourut du temps de Louis XIV, à la ménagerie de Versailles, avait assez de discernement pour voir quand on se moqait de lui. Un peintre voulant le dessiner dans une attitude extraordinaire, qui était de tenir sa trompe élevée et sa gueule ouverte, le valet du peintre, pour lui faire garder cette situation, lui jetait des fruits dans la bouche, et le plus souvent n'en faisait que le geste. A la fin l'éléphant s'en indigna; et, comme s'il se fût aperçu que l'envie que le peintre avait de le dessiner était la cause de cette importunité, au lieu de s'en prendre au valet, il s'adressa au mâ̂. tre, et lui lança par la trompe un jet d'eau, qui gâta le papier sur lequel il travaillait.

L'éléphant est sujet à des accès de colère, mais cette colère s'appaise promtement. Il ne manque pas d'ailleurs d'une certaine générosité. Un homme qui gou- 
DES ENFANTS.

vernait depuis longtemps un éléphant qu’il avait roujours trouvé docile, tant qu'il n'avait exigé de lui que des choses raisonnables, le malıraita un jour injustement. L'animal, outré de ce mauvais procédé lua son maître; cet homme avait une femme et deux fils encore très-jeunes. Sa femme au desespoir présenta ses enfants à l'éléphant, comme pour lui dire de les immoler aussi. Ce tableau touchant, attendrit l'animal irrité ; et, pour réparer antant qu'il était possible le meurtre qu'il venait de commettre, il prit doucement avec sa trompe, l'aîné des deux enfants, le plaça sur son dos, le regarda dès-lors comme son mâ̂Ire, et se laissa toujours conduire par lui. 


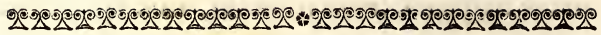

\section{LE LI昆VRE.}

Ce petit animal, dont la race est répandue avec tant de profusion sur la surface de la terre, paraît être destiné aux plaisirs de l'homme, encore plus qu'à ses besoins. Les Lièvres de la Laponie et des pays septentrionaux deviennent blancs l'hiver, et reprennent leur couleur fauve en été. On en voit aussi de blancs dans nos provinces, surtout en Pologne. Le lièvre a peu d'industrie. Naturellement peureux, l'agitation de l'air, le bruit d'une feuille, en voilà assez pour le meltre en alarmes ; encore s'il avait l'instinct de se faire un terrier, mais se croyant caché dans un sillon entre quelques légères moltes de terre, il ne doit souvent son salut qu'à son caractère inquiet et défiant, à la finesse de l'organe de l'ouie, et à la rapidité de sa course. L'Hiver il se gîte à l'abri du nord, et l'été, à l'abri du midi dans les blés. Lorsqu'il 
sont grands, il abat les épis pour se faire des sentiers et fuir librement à l'approche des chiens. Le lièvre n'ayant aucun moyen de défense, il ne trouve souvent son salut que dans la fuite. Sans cesse aux aguets pour découvrir le danger, et doué d'un ouïe excellente, il prend la fuite à la première apparence de danger.

Quoiqu'on ait dit, le lièvre est un animal intelligent et capable de ruse pour éviter le danger. Lorsque la terre est couverte de neige, ils savent que l'empreinte de leurs pas peut mettre le chasseur sur leurs traces, ils ont soin alors de l'embrouiller en passant et repassant vingt fois dans le même endroit, puis s'élançant tout d'un coup du milieu de ces pas confondus ils vont tomber dans un buisson ou un sillon profond où ils restent cachés sans faire le moindre mouvement, en sorte que les chiens et les chasseurs passent à côté d'eux sans les apercevoir.

On en a vu se cacher au milieu d'un troupeau de moutons. D'autres pourstiivis depuis longtemps et harassés de fatigue 
vont pousser un autre lièvre hors de son gîte afin qu'il se mette à courir à son tour et ils se reposent dans son gîte.

La femelle du lièvre qu'on appelle hase, porte un mois entier, et donne naissance à trois ou quatre petits, qui au bout de vingt jour's, quittent le gîte natal et se dispersent pour vivre solitairement. C'est un plaisir de les voir sauter, gambader au clair de la lune. Ils vivent de grains et de plantes aromatiques, telles que la milrjolaine, le serpolet, etc.

La chasse du lièvre est une des plus agréables. On chasse le lièvre avec des chiens d'arrêt, ou on le furce à la course avec des levriers ou des chiens courants.

Les loups, les aigles, les renards, les ducs et les buses sont pour cet animal sans défense des ennemis aussi redoutables que l'homme. Outre les plaisirs de la chasse, le lièvre fournit encore à nos tables un excellent mets. La chair des femelles est plus délicate. On préfere le lièvre des montagnes à ceux des plaines. La loi des Juifs et celle de Mahomet interdi- 
sent la chair du lièrre comme celle du cochon. La fourure des lièvres d'Amérique est excellente. Leur poil ne tombe jamais. Les chapeliers font usage du poil de lièvre comme de celui du lapin.

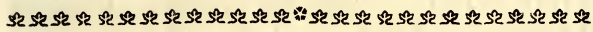

\section{LE GERF.}

\section{(Planche I, fig. 11. )}

Le cerf' est l'un de ces animaux innocents, doux et tranquilles, qui ne semblent être faits que pour embellir, animer la solitude des forêts, et occuper loin de nous les retraites paisibles de ces jardins de la nature. Sa forme élégante et légère, sa taille aussi svelte que bien prise, ses membres flexibles et nerveux, sa tête parée plutôt qu'armée d'un bois vivant, et qui, comme la cîme des bois, tous les ans se renouvelle; sa grandeur, sa légèreté, sa force le distinguent assez des autres habitants des bois. En général, les cerfs sont portés à demeurer les uns avec 
62

LE BUFFON

les autres, à marcher en compagnie, et ce n'est que la crainte ou la nécessité qui les disperse ou les sépare. Le cerf paraît avoir l'œil bon, l'odorat exquis et l'oreille excellente. Lorsqu'ilyeurve écouter, il lève la tête, dresse les oreilles, et alors il entend de fort loin : lorsqu'il entre dans un petit taillis ou dans quelque autre endroit à demi-couvert, il s'arrête pour regarder de tous côtés, et cherche ensuite le dessous du vent pour sentir s'il n'y a pas quelqu'un qui puisse l'inquiéter. II est d'un naturel assez simple, et cependant il est curieux et rusé : lorsqu'on le siffle ou qu'on l'appelle de loin, il s'arrête tout court et regarde fixement et avec une espèce d'admiration, les voitures, le bétail , les hommes; et s'ils n'ont n'y armes, ni chiens, il continue à marcher dun pas réglé et tranquille, et jasse son chemin fièrement et sans fuir. Il paraît aussi écouter avec autant de tranquillité que de plaisir, le chalumeau ou le flageolet des bergers, et les chasseurs se servent quelquefois de cet artifice pour le rassu- 
DES ENFANTS.

rer. En général il craint beaucoup moins l'homme que les chiens, et ne prend de la défiance et de la ruse, qu'à mesure et qu'autant qu'il aura été inquiété. Il mange lentement et choisit sa nourriture; il nage très bien. La biche est la femelle du cerf. 


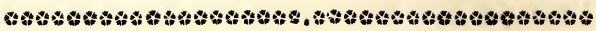

\section{LE RHINOGÉROS.}

(Planche III , fig. 1.)

Le Rhinocéros a au moins quatre mètres de longeur, el deux de hauteur. L'arme offensive qu'il porte sur le nez, est une corne très dure, qui parvient jusqu'à la longueur de trois ou quatre pieds. Son corps, et tous ses membres sont couverts d'une cuirasse impénétrable aux griffes des animaux et au fer du chasseur. Sa couleur est noirâtre. Il a les yeux très petits. Sa lèvre supérieure, qu'il peut allonger jusqu'à six ou sept pouces, est terminée par un appendice pointu, assez flexible pour faire l'office d'une main. Ses oreilles, toujours droites, sont courtes, l'extrémité de la queue est garnie d'un bouquet de soie très solide et très dure, ses jambes sont courtes rondes, et épaisses, et ses pieds soat armés de trois grands ongles 



\section{PI. III.}
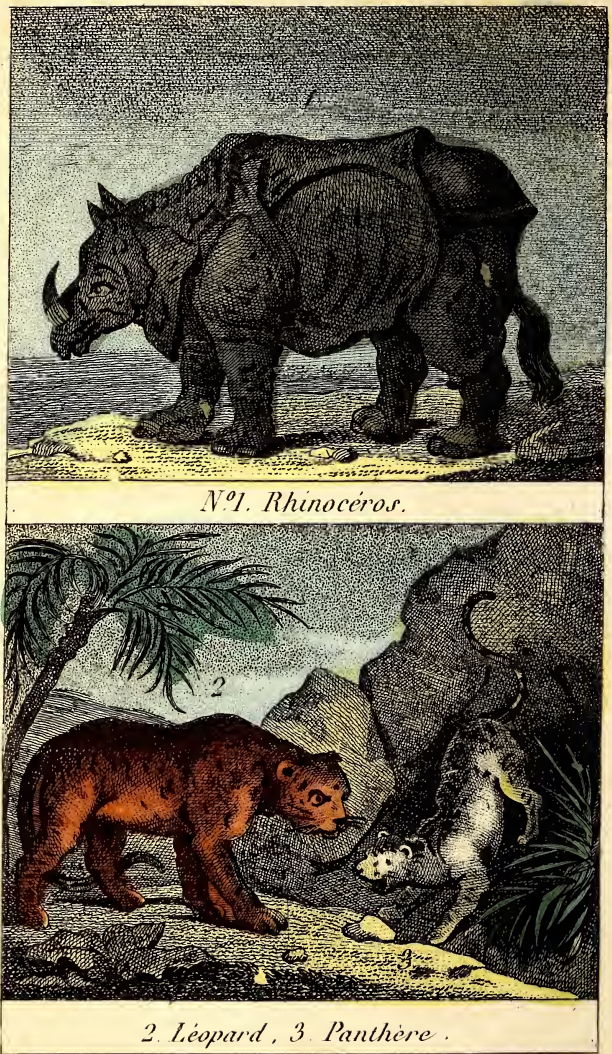
DES ENFANTS.

Sanș être ni féroce, ni carnassier, le rhinocéros est cependant intraitable : il est à peu près en grand, ce que le cochon est en petit, brusque sans intelligence et sans docilité, il se plaît dans les lieux humides et marécageux. Sa peau fait le cuir le meilleur, et le plus dur qu'il y ait au monde.

Cet animal se nourrit d'herbes el de grains; il n'attaque point les hommes, à moins qu'il ne soit provoqué. Comme les balles s'applatissent sur son cuir, et que les lances ne sauraient l'entamer, les chasseurs profitent du moment où il est endormi pour le percer au ventre, aux yeux ou autour des oreilles, seuls endroits qui soient pénétrables. Le rhinocéros que nous venons de décrire ne se trouve que dans les contrées les plus chaudes de l'Asie. En général, il est beaucoup plus rare que l'éléphant. Comme le temps de son accroissement paraît être d'environ quinze ans, on croit qu'il en peut vivre cent. La femelle porte pendant quatorze ou quinze mois, et ne produit 
66 LE BUFFON

qu'un petit. Le meilleur moyen d'échapper à la fureur de cet animal quand on en est poursuivi, est de faire beaucoup de détour's : ses yeux sont placés de manière qu'il ne peut pas voir que devant lui; il est d'ailleurs si lent à se détourner, quoique léger à la course, que son ennemi est bientôt hors de danger.

Les Indiens mangent la chair des jeunes rhinocéros; celle des vieux est coriace. 


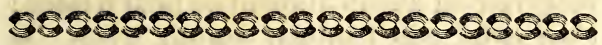

\section{LE CHAMEAU.}

(Planche IV , fig. 2.)

Cet animal, dont la longueur moyenne est de trois mètres et demi sur deux et demi de hauteur, a les cuisses et la queue fort petites, les jambes longues, le pied fourchu comme le bœuf, la tête petite et allongée, les yeux gros et saillants, les oreilles courtes, le front revêtu d'un duvet qui ressemble à de la laine, et le cou extrêmement long. Tout son corps est couvert de longs poils roux.

Ses principaux caractères distinctifs sont d'avoir au milieu du dos une bosse charnue assez grosse, et cinq estomacs, tandis que les autres animaux ruminants (1) n'en ont que quatre. Ce cinquième estomac est un

(1) On appelle animaux ruminants, ceux qui remâchent ce qu'ils ont avalé, 
réservoir où aucun aliment ne peut passer; c'est celui que l'animal emplit d'eau, et d'où il la fait refluer à volonté dans un autre estomac. Elle s'y conserve plus de huit jours sans se corrompre. Les callosités que l'on remarque sur la partie inférieure de sa poitrine, ne viennent que de son attitude dans les instants du repos. Il s'accroupit au lieu de se coucher sur le côté.

Le chameau est originaire d'Arabie. Comme les premiers hommes civilisés habitaient cette partie de l'Asie, cet animal utile ne tarda pas à devenir une de leurs conquêtes. L'industrie le répandit ensuite jusqu'en Afrique. Aucun historien ne dit qu'on ait jamais vu des chameaux sauvages. Sans le secours de cet animal, aussi sobre qu'il est vigoureux, il eût été impossible de traverser ces immenses solitudes, où le voyageur ne trouve que des sables brûlants. Lui seul rend peut-être autant de services que le cheval, l'âne et le boeuf réunis. Il n'est pas plus délicat que l'àne sur la qualité de la nourriture; sa chair, quand il est jeune, est aussi bonne 


\section{DES ENFANTS.}

et aussi saine que celle du veau, son poil est plus beau et plus recherché que la plus belle laine. La femelle donne du lait pendant plus de temps que la vache: il n'y a pas jusqu'à ses excréments dont on ne tire avantage, quand ils sont desséclés, puisque, mis en poudre, ils servent de litière et qu'on en fait des mottes à brûler, chose précieuse dans les déserts où il ne se trouve pas un arbre.

Les plus grands chameaux portent de cinq à six cents kilogrammes ; les plus petits trois cents à trois cents cinquante. Dans les voyages de long cours, on règle leur marche à dix ou douze lieues par jour, quoiqu'ils puissent en faire bien davantage. Pour prendre la charge, ils fléchissent les genoux à la voix de leur conducteur, mettent le ventre contre terre, et demeurent dans celte posture jusqu'à ce qu'on leur ait commandé de se relever. Lorsqu'ils se sentent surchargés, ils demeurent constamment couchés, afin qu'on les allége. Du reste leur obéissance au maìtre qui les conduit est admirable. Ils lui 
épargnent jusqu'à la peine d'élever les fardeaux, en venant se concher entre les ballots, et en attendant patienment qu'on les ait attachés pour se relever. Celui qui conduit une troupe de chameaux, les précède tous et leur fait prendre le même pas que sa monture, en charmant leur ennui par la voix ou par le son de quelque instrument.

Le chameau est capable de demeurer chargé pendant trente ou quarante jours, et d'en passer huit ou dix sans boire et sans manger. Sa nourriture commune est le maïs ou blé de Turquie et l'avoine. A leur défaut, il se contente de branches d'arbres, de ronces et de joncs. Loin d'aimer l'eau claire, il la trouble avec le pied pour la rendre bourbeuse. La femelle ne produit qu'un petit qu'elle porte environ un an. 


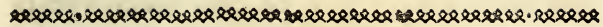

\section{LE NILGAUT.}

Cet animal, originaire des climats chauds, est de la taille d'environ 1 mètre 30 centimètres. Ses cornes ont 17 centimè tres de long. Sur ses épaules s'élève une espèce de bosse, surmontée d'une petite crinière, qui prend son origine au sommet de la tête; une touffe de longs poils noirs pend au milieu de la poitrine. Tout le corps est d'un gris d'ardoise, la tête d'un fauve mêlé de grisâtre, le tour des yeux d'un fauve clair, avec une petite tache blanche à l'angle de chaque oeil ; les oreilles, qui sont grandes et larges, sont rayées de trois bandes noires vers leurs extrémités; le sommet de la tête est garni d'un poil noir, mêlé de brun, qui forme sur le haut du front une espèce de fer à cheval. Il a sous le cou, près de la gorge, une grande tache blanche. La couleur du ventre est d'un gri d'ardoise comme celle du corps ; les jambes 
de devant et les cuisses sont noires sur la face extérieure, et d'un gris foncé sur la face intérieure. Le pied ressemble à celui d'un cerf, el la queue qui se termine par une touffe de grands poils noirs, est d'un gris d'ardoise sur le milieu, et blanche sur les côtés. Le nilgaut n'est point agile comme le cerf auquel il ressemble beaucoup, il court au contraire de mauvaise grâce, ayant les jambes trop massives, et cẻlles de derrière plus courtes que celles de devant. Cet animal est doux, et même familier, quoique très vif. Il mange de l'avoine, et, de préférence, de l'herbe fraiche : comme il produit dans nos climats, ce serait une bonne acquisition à faire. Cn en retirerait de bonne viande, du suif et des cuirs fermes et épais. 


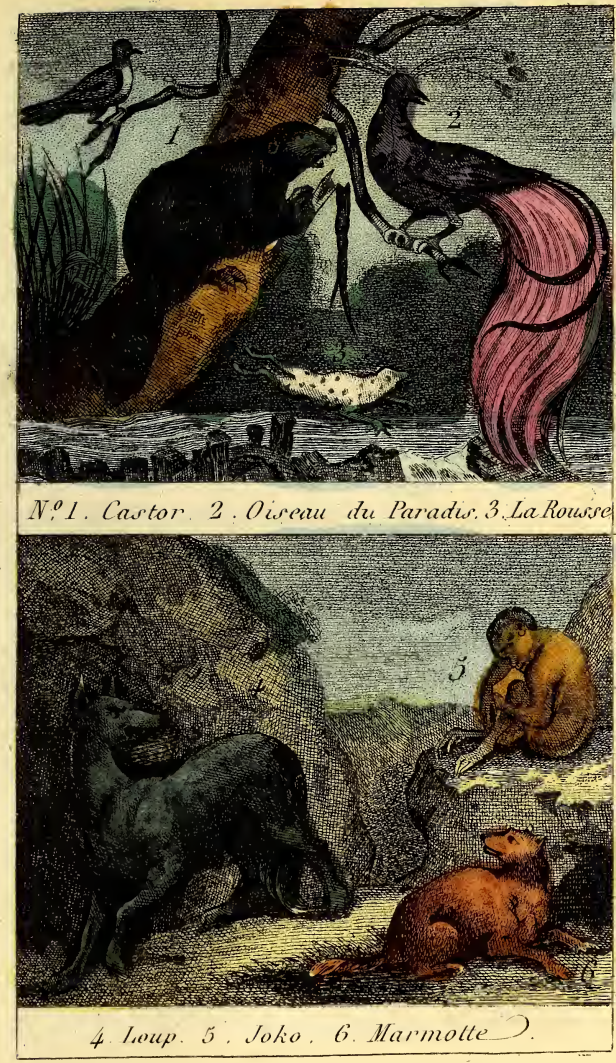





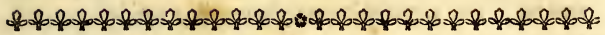

\section{LE GASTOR.}

(Planche IX, fig. 1.)

Le Castor habite le voisinage des eaux et vit de poissons, d'écrevisses, et surtout de l'ècorce tendre des arbres aquatiques. Ses pieds de derrière ont, au lieu de doigts, une forte membrane qui en fait des nageoires. Ceux de devant sont courts, et il s'en sert avec beaucoup d'adresse. Ses dents, au nombre de vingt, sont extrêmement fortes. Tout son corps, à l'exception de la queue est couvert de deux sortes de poils : d'un duvet très-fin et très serré, long d'un pouce, et d'un poil long, qui garantit le duvet de la boue. Sa queue, large de 12 centimètres, est très épaisse, couverte d'une peau écailleuse et longue de 33 centimètres. La couleur du castor est ordinairement brune. On en trouve cependant de noirs et même de 
tout blanes. Les femelles portent quatre mois, et produisent deux ou trois petits. Cet animal est court et ramassé. Il pèse 25 à 30 kilogrammes. Dans les cantons les plus reculés du nord de l'Europe et de l'Amérique, les castors élèvent des digues qui retiennent les eaux des rivières à la hauteur qui leur convient, et ils y construisent des habitations en forme de terriers où ils demeurent en famille. Pour couper un arbre, un nombre d'ouvriers, proportionné à la grosseur, l'altaque successivement avec les dents. Les grosses branches servent à faire des pieux pour les digues, les petites entrelacées et enduiles d'une terre grasse, remplissent les vides. La queue de l'animal sert de voiture et de truelle pour amener et maçonner le mortier. Les fondements de ces digues ont ordinairement 3 à 4 mètres d'épaisseur et vont en diminuant de manière à n'avoir plus qu'un mètre au sommet. Le côté du courant d'eau est toujours en talus, et le côté opposé est d'aplomb. Le même art se fait remarquer dans la construction des ca- 


\section{DES ENFANTS.}

banes, ordinairement bâties sur pilotis. Leur figure est ronde ou ovale. Elles sont voûtées en anses de panier. Les matériaux ne diffèrent de ceux des digues, qu'en ce qu'ils sont moins gros. L'enduit intérieur de la terre glaise n'y laisse pas le moindre jour. Les deux tiers de l'édifice sont hors de l'eau. C'est dans cette partie que chaque castor a sa petite demeure. II prend soin de la garnir de feuillages. Jamais on n'y voit d'ordures. Les cabanes ordinaires servent de logement à huit ou dix castors. Il s'en trouve, mais rarement, qui en contiennent jusqu'à trente. Elles sont toujours assez près les unes des autres pour que la communication soit facile et la réunion de ces cabanes forme une sorte de bourgade.

Ces ouvrages sont toujours finis, et la provision se trouve faite avant l'hiver. Chaque castor n'a qu'un magasin commun pour toute la famille. Dans les contrées où l'homme s'est établi, ces anirnaux ont perdu, avec l'industrie, cet instinct social si digne d'admiration, et vivent 
solitairement dans des boyaux longs et tortueux qu'ils se creusent le long des fleuves.

Le poil fin du castor sert à faire des chapeaux de feutre d'un grand prix. L'espèce du castor diminue de jour en jour. Elle est actuellement confinée dans les parties les plus désertes et les plus reculées de l'Amérique septentrionale. Il en existe encore quelques-uns dans le Languedoc, et dans les îles du Rhône. 


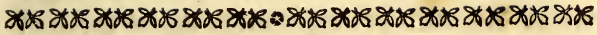

\section{LE JOCKO.}

(Planche IX, fig. วั.)

Le Jocko porte aussi le nom de Chimpauzé ou Kimpézay. C'est l'espèce de singe qui se rapproche le plus de l'homme par l'intelligence.

Il y a peu d'années, il y avait à Paris un Chimpauzé femelle qu'on nommait Jacqueline. Cet animal, bon, doux et caressant, reconnaissait parfaitement les personnes qui allaient le voir et leur faisait plus de caresses qu'aux autres. M. Werner, célèbre peintre d'histoire naturelle ayant été chargé de la dessiner, Jacqueline fut au comble de la surprise en voyant son portrait. Elle demanda par signes un papier et du crayon, se plaça gravement à la table de l'artiste et se mit à tracer des traits informes. Elle voulut aussi coudre à l'imitation d'une femme qu'elle vit raccommo- 
dant du linge, mais s'étant piqué les doigts elle se dégoûta promptement de ce métier.

Jacqueline avait un chien et un chat qu'elle aimait beaucoup et qu'elle faisait coucher à côté d'elle dans son lit, l'un à droite et l'autre à gauche. Quand le chien et le chat se querellaient, Jacqueline les séparait et les châtiait sévèrement pour les obliger à vivre en bonne intelligence.

Cet intéressant animal est mort d'une maladie de poitrine. Elle n'avait que deux ans et demi.

Le Jocko ou chimpauzé atteint la taille de l'homme. Il habite les mêmes contrées que l'orang-outang. 


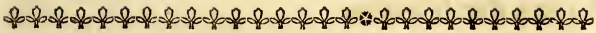

\section{I'ORANG-OUTANG.}

(Planche VI, fig. 5.)

L'Orang-Outang a la face plate, nue et basanée, les oreilles, les mains, la poitrine et le ventre nus, une espèce de chevelure sur la tête, du poil lung, mais rare sur les épaules et les reins, les fesses charnues, et des mollets comme l'homme; ce qui lui donne la faculté de se tenir debout. Il n'a point, comme les guenons et les baboins , des callosités sur les fesses.

Son talon est un peu plus élevé que celui de l'homme, ce qui fail qu'il court plus aisément qu'il ne marche; il a aussi les hanches plus serrées, le cou moins long, le nez encore plus écrasé que celui du nègre, le front moins grand, le menton moins relevé, les oreilles plus grandes, les yeux plus voisins l'un de l'autre.

De ces nombreux rapports de confor- 
mation, résultent des mouvements pareils à ceux des hommes.

Ces animaux se trouvent en Afrique, et dans les climats chauds de l'Asie : ils se nourrissent de fruits et de graines; leur force est, dit-on, si extraordinaire, que dix hommes robustes ne peuvent en arrêter un seul. Dans l'état sauvage ils se rendent redoutables aux nègres, construisent des cabanes pour s'y mettre à l'abri du soleil et de la pluie, et dorment sur des arbres. Leur taille s'élève quelquefois à deux mètres. L'orang-outang a l'air triste et la démarche grave : il est d'un naturel doux, et s'apprivoise si aisément, que, quand on le prend jeune, il obéit au moindre signe, et rend autant de service dans une maison qu'un domestique ordinaire. On en a vu s'asscoir à table, déployer leur serviette se servir de la cuillère, du couteau et de la fourchette, se verser à boire dans un verre ${ }^{6}$ choquer le verre lorsqu'ils y étaient invités, aller prendre une tasse ou une soucoupe, l'apporter sur la table, y mettre du sucre, y verser du thé, le laisser refroi- 
DES ENFANTS.

dir pour le boire, se promener gravement avec les hommes, et leur présenter la main pour les reconduire.

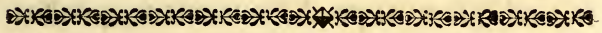

\section{LE MALBROUGK.}

(Planche VI, fig. 7.)

Le Malbrougk, qui a environ un demi mètre de longueur, ne marche qu'à quatre pieds : il a la face grise, les yeux grands, les paupières couleur de chair, ainsi que les oreilles, qui sont grandes et minces, le museau large, le front ceint d'un bandeau gris, et la queue de la longueur du corps : son poil varie par la couleur; car on trouve des malbrougks noirs, blancs, gris , rougeâtres, et d'un jaune brun; cependant ces derniers sont les plus communs. Cette espèce a à peu près les mêmes habitudes que les autres guenons : elle vit dans les forêts, de graines, de cannes à sucre et d'insectes, et prend pour le pillage les mêmes 
précautions; on la trouve au Bengale et dans quelques autres contrées de l'Inde. Dans les cantons où la religion défend de faire aucun mal aux animaux, ces guenons se multiplient si prodigieusement, qu'elles viennent par troupes jusque dans les villes, et entrent avec tant de liberté dans les maisons, que les marchands de fruits ne savent comment se mettre à l'abri de leurs recherches. On cite même une ville, dont les habitants garnissent les terrasses de leurs maisons d'une provision de fruits, que les singes du voisinage viennent chercher deux fois par semaine. Il y a dans cette ville plusieurs hôpitaux pour les singes estropiés ou malades. La grande quantité de singes empêcherait qu'aucun oiseau ne pût nicher sur les arbres, si ces animaux n'avaient eux-mêmes pour ennemis de gros serpents qui leur font une guerre continuelle. 


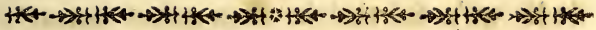

\section{LA TORTUE GEOMETREQE.}

\section{(Planche I, fig. 5.)}

Celte Tortue terrestre a la couverture supérieure des plus bombées. Les conleurs dont elle est variée, la rendent très agréable à la vue. Les lames qui revêtent les deux couvertures et qui sont ordinairement au nombre de seize sur le disque , de vingt-trois sur lés bords de la carapace et de douze sur le plastron, se relèvent en bosse dans leur milieu; elles sont fortement striées, séparées les unes des autres par des espèces de sillons assez profonds, et la plupart à six côtés. Lieur couleur est noire : le centre présente une tache jaune, d'où partent plusieurs rayons de la même couleur. Ces lames présentent ainsi une sorte de réseau, de couleur jaune, composé de lignes très-distinctes , dessinées sur un fond noir, et ressem: 
blant à des figures géométriques : c'est de là qu'a été tiré le nom qu'on donne à l'animal. On trouve cette tortue particulièrement en Asie. Sa chair est un mets délicat.

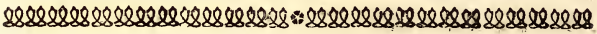

\section{LE MIDAS.}

Il y a des tortues dont l'écaille du dos a jusqu'à 1 mètre et demi de longueur et dont le poids surpasse trois cents kilogrammes. On en mange la chair qui est fort délicate. Leur écaille sert à faire une infinité d'ustensiles très jolis : autrefois les Indiens se servaient des plus grandes en guise dee boucliers, ou pour les canots, ou pour les toits.

La tortue est l'animal le plus aisé à prendre : il n'y a qu'à épier le moment où elle sort de la mer le soir, s'approcher une perche à la main par derrière, la renverser avec sur le dos; elle est prise. Mais si l'on s'approche par devant, elle 
vous jette au visage une quantité de sable. Celle que l'on appelle Midas ou géant est la plus grosse de toutes : avec dix hommes sur le dos, elle peut marcher comme si elle n'avait rien, et le char le plus pesant peut passer sur elle sans l'écraser ni même la faire plier.

L'espèce nommée tortue squameuse, a l'écaille la plus belle et la meilleure, et son nom vient de ce que ses écailles, qui out une palme de diamètre, sont posées les unes sur les autres comme celles des poissons. Les tortues terrestres qui sont plus petites que les autres, et auxquelles il parât qu'il faut réunir les tortues appelées d'eau douce, puisqu'elles ne peuvent vivre toujours dans l'eau, se trouvent aussi dans le midi de la France, autour de Marseille et de Bordeaux. 


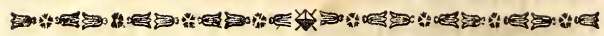

\section{LA MARMOTTE.}

(Planche IX, fig. 6.)

La Marmotte ressemble au lièvre par la tête, au blaireau par le poil et les ongles, et à l'ours par les pieds. Elle a les oreilles et la queue très courtes, le poil du dos d'un roux brun et rude, et celui du ventre roussâtre, doux et fourni. Quoique moins grande que le lièvre, elle est plus forte et plus trapue. Ordinairement elle se tient assise comme l'écureuil, et se sert de ses pieds de devant pour porter à sa bouche.

Plusieurs marmottes se réunissent aux approches de l'hiver, et se construisent, sur le penchant d'une montagne, un grand terrier à deux ouvertures, qu'elles approvisionnent de foin, pour se nourrir jusqu'au temps de leur engourdissement. Cette demeure souterraine a la forme d'un 
DES ENFANTS.

$X$ grec. La marmotte habite les hauts sommets des Alpes, des montagnes de la Suisse et des Pyrénées. On l'accoutume facilement à la vie domestique. Elle mange de tout, des fruits, du pain, de la chair, et aime surtout beaucoup le lait.

Les petits Savoyards apportent des marmottes en France et les leur font faire des exercices tels que de saisir un bâton, y monter, danser au son de la vielle.

La marmotte fait entendre, lorsqu'on la caresse, un murmure qui ressemble au cri d'ún petit chien. Un sifflement assez aigu annonce son mécontentement ou la douleur. Elle ne produit qu'une fois l'année. Chaque portée est de trois ou quatre petits. 


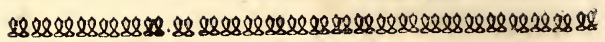

\section{L'IGUANE.}

L'iguane forme par l'éclat de ses couleurs et le brillant de ses écailles, un des principaux ornements de ces immenses forêts qui couvrent une partie de l'Amérique méridionale. Il est aisé de le distinguer par la grande poche qu'il a au-dessous du cou, et par la crète dentelée qui s'étend depuis la tête jusqu'à l'extrémité de la queue, et qui garnit aussi le devant de la gorge.

La longueur de ce lézard est assez souvent d'un mètre et demi ; et sa couleur qui varie suivant l'âge, le sexe et le pays , est tantôt bleuâtre, tantôt verte mélée de jaune. Il a la tête aplatie par-dessus et comprimée par les côtés. Sa queue, qui est ronde présente ordinairement des anneaux de diverses couleurs. Cet animal ne cherche point à nuire, et ne se nourrit que de végétaux et d'insectes. Il ne laisse poing 
cependant d'intimider, lorsqu'agité par la colère, et animant son regard, il fait entendre un sifflement, secoue sa longue queue, gonfle sa gorge, et redresse ses écailles hérissées de pointes. Lorsqu'il a reçu quelque éducation, il reste volontiers dans les jardins, et passe même la plus grande partie du jour dans les appartements. Sa chair est excellente à manger. La femelle pond depuis treize œufs jusqu'à vingt-cinq.

Les iguanes se retirent dans des creux de rochers ou dans des trous d'arbres. On les voit s'élancer avec une agilité merveilleuse jusqu'au plus haut des branches, autour desquelles ils s'entortillent de façon à cacher leur tête au milieu des replis de leur corps. Lorsqu'ils sont repus, il vont se reposer sur les rameaux qui avancent audessus de l'eau, et demeurent comme engourdis. C'est ce moment que l'on chuisit au Brésil pour les prendre. Lorsqu'un chasseur voit un de ces animaux ainsi étendu sur des branches, et s'y pénétrant de l'ardeur du soleil, il commence à sif- 
90 LE BUFFON

fler : l'iguane qui semble prendre plaisir à l'entendre, avance la tête peu à peu ; le chasseur s'approche en continuant de siffler, et chatouille la gorge de l'animal avec le bout d'une perche : celui-ci souffre cette espèce de caresse sans témoigner aucune peine, et se retourne même, comme pour en jouir avec volupté : lorsqu'il a porté sa tête hors des branches, le chasseur lui passe au cou une corde nouée en forme de lacs, qu'il a au bout d'un bàton, et le fait tomber à terre par une violente secousse.

On trouve des iguanes en Afrique et en Asie; mais ils y sont bien moins communs qu'en Amérique. 


\section{LE LÉZARD VERT.}

(Planche I, fig. 8. )

La nature en formant le lézard vert, n'a fait pour ainsi dire, qu'agrandir le lézard gris, et le revêtir d'une parure plus brillante. Le dessus de son corps est d'un vert plus ou moins mêlé de jaune, de gris, de brun, et même quelquefois de rouge; mais c'est surtout dans les climats chauds qu'il brille avec plus d'éclat : il y parvient aussi à une grandeur considérable (quelquefois jusqu’à 75 centimètres. Quoique peu élevés sur leurs pattes, ils courent avec agilité, et partent avec assez de promptitude pour donner un premier mouvement de surprise et d'effroi, lorsqu'ils s'élancent au milieu des broussailles ou des feuilles sèches. L'habitude qu'ils ont de saisir par l'endroit le plus sensible, c'est-à-dire par les narines, les diverses espèces de ser- 
pents avec lesquels ils sont souvent en guerre, fait qu'ils se jettent au museaı des chiens, et y mordent avec tant d'obstination, qu'ils se laissent emporter et même tuer plutôt que de lâcher prise. Aucune espèce de lézard n'est venimeuse.

0000000000000000000000000000

\section{LE LEZARD GRIS.}

Ce petit animal, si commun dans le pays que nous habitons, paraît être le plus doux, le plus innocent, et l'un des plus utiles des lézards. S'il n'a pas reçu de la nature une parure bien éclatante, il a de quoi intéresser par la légèreté de la taille, par l'agilité de ses mouvements et la rapidité de sa course. Ayant besoin d'une température douce, il cherche les abris ; et lorsque, dans un beau jour de printemps, une lumière pure éclaire vivement une muraille ou un gazon en pente, on le voit s'y étendre avec une espèce de volupté. Il marque son plaisir par les ondulations de sa queue; 
il fait briller ses yeux, et se précipite comme un trait pour saisir une petite proie, ou pour trouver un abri plus commode. Bien loin de fuir à l'approche de l'homme, il paraît le regarder avec complaisance; mais au moindre bruit qui l'effraie, à la chute d'une feuille, il se roule et se laisse tomber, ou bien il s'élance, disparaît, se montre de nouveau, et décrit en un instant plusieurs circuits tortueux que l'oil a de la peine à suivre. La couleur grise que présente le dessus de son corps, est variée par un grand nombre de taches blanchâtres , et par trois bandes presque noires, qui parcourent la longueur du dos. Le ventre est peint de vert changeant en bleu.

On ne craint point ce paisible animal : il échappe communément avec rapidité, lorsqu'on veut le saisir; mais, lorsqu'on l'a pris on le manie sans qu'il cherche à mordre. Les enfants en font un jouet; et, par une suite de sa grande douceur, il se familiarise avec eux, approche innocemment sa bouche de la leur, et suce leur salive avec avidité. Malheureusement il ne reçoit 
pas toujours caresse pour caresse, et l'enfance souvent ingrate, parce qu'elle ne se donne pas la peine de réfléchir, prend plaisir à lui faire perdre une partie de sa queue, qui est très fragile. Cette queue, lorsqu'elle a été brisée par quelqu'accident, repousse quelquefois ; et suivant qu'elle a été divisée en plus ou moins de partie, elle est remplacée par deux, et même par trois queues plus ou moins parfaites.

Pour saisir les mouches et autres insectes dont il se nourrit, le lézard gris darde avec vitesse une langue garnie de petites aspérités qui lui aident à retenir sa proie. Le tabac pulvérisé est presque toujours un poison mortel pour lui. Comme les autres quadrupèdes ovipares, il peut vivre beaucoup de temps sans manger; et l'on en a gardé pendant six mois dans une bouteille, sans leur donner aucune nourriture. Il passe la saison du froid dans des trous d'arbres ou de murailles, ou dans des creux sous terre. 


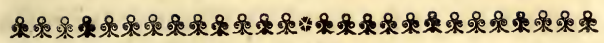

\title{
LE GROCODILE.
}

\author{
(Planche V, fig. 3.)
}

Cet animal énorme ne se trouve que dans les parties les plus chaudes de l'Afrique et de l'Asie dont il habite les fleuves ; il se nourrit de proie, il dévore les autres animaux, il attaque même l'homme, mais cen'est pas, comme le tigre, pour assouvir un appétit cruel ; mais uniquement pour satisfaire à des besoins d'autant plus impérieux, qu'il a une masse considérable à entretenir.

La forme générale du crocodile est assez semblable en grand, à celle des autres lézards ; mais en examinant ses caractères particuliers, on trouve qu'il a la tête allongée, aplatie et fortement ridée; le museau gros, la gueule fendue jusqu'audelà des oreilles. Ses dents, quelquefois au nombre de trente-six dans la mâchoire su- 
périeure, et de trente dans la mâchoire inférieure, sont fortes, pointues, inégales en longueur, placées sur un seul rang, et disposées de manière que, quand la gueule est fermée, elles passent les unes entre les autres.

Comme cet animal n'a point de lèvres , il montre ses dents lorsqu'il marche ou qu'il nage avec le plus de tranquillité; et ce qui ajoute encore à cet air de furie qui tient à sa conformation, c'est que ses yeux étincelants, très rapprochés l'un de l'autre, garnis de deux paupières dures, fortement ridées et surmontées d'un rebord dentelé, lui donnent une sorte de regard sinistre; sa queue est très longue et d'une forme aplatie, assez semblable à celle d'un aviron, ce qui lui facilite beaucoup les moyens de nager. L'armure qui revêt tout son corps, excepté la léte, est composée d'écailles. Celles qui couvrent les flancs, les pattes et la plus grande partie du cou, sont presques rondes, de grandeurs différentes, et distribuées irrégulièrement. Celles qui défendent le dos et le dessus de la queue, sont carrées, et 
DES ENFANTS.

forment des bandes transversales. II faut donc, pour blesser le crocodile, le frapper dans les jointures des bandes qui ne présentent que la peau. La couleur des crocodiles tire sur le brun verdâtre, plus ou moins nuancé d'un vert faible, par taches et par bandes. Leur taille ordinaire est de 5 à 8 mètres. Ils fréquentent de préférence les rives des grands fleuves. La femelle pond environ soixante oufs ; mais heureusement ces œufs sont recherchés par la mangouste, par les singes, et par plusieurs espèces d'oiseaux d'eau, de manière qu'un grand nombre de crocodiles sont détruits avant d'éclore. Leur chair, que certains peuples de l'Inde et de l'Amérique trouvent délicate, a toujours rebuté les Européens par son odeur de musc. 


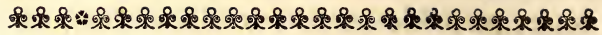

\section{LE GAMÉLÉNO}

(Planche V, fig. 4.)

Le nom de ce lézard sert, depuis longtemps, à désigner la flatterie, parce qu’il n'a pas la couleur qui lui soit propre, comme le flatteur n'a pas d'avis à lui. Sa tête aplatie par-dessus, l'est aussi par les côtés; et cinq arrêtes, dont deux partent du museau, deux des coins de la gueule, et la troisième du sommet de la tête, forment au-dessus une pyramide à cinq faces, dont la pointe est tournée en arrière, sa gorge est comme gonflée, et représente une espèce de poche, mais moins grande que celle de l'iguane. On voit sur sa peau de petites éminences comme le chagrin. Ses yeux sont gros et saillants; et, ce qui est particulier, ils sont mobiles indépendamment l'un de l'autre, de manière que l'animal peut avec 
DES ENFANTS.

l'un regarder en avant, tandis qu'avec l'autre il regarde en arrière, ou bien, voir de l'un les objets placés au-dessus de lui , pendant que de l'autre il aperçoit ceux qui sont situés au-dessous. Le caméléon est donc unique par plusieurs caractères très remarquables ; mais les singularités dont nous venons de parler, ne sont pas les seules qu'il présente. Plus élevé sur ses jambes que la plupart des autres lézards, il a moins l'air de ramper l'orsqu'il marche; mais comme la peau de ses jambes descend jusqu'au bout des doigts, il n'a pas d'appui bien ferme sur la terre : aussi aime-t-il mieux s'accrocher aux arbres avec ses ongles et avec sa queue, qui est prenante comme celle des sapajous. Du reste, soit qu'il grimpe sur les arbres, soit qu'il marche sur la terre, ses mouvements sont toujours lents.

Quoiqu'il soit difficile d'assigner la couleur du caméléon, on peut dire en général qu'il est d'un gris plus ou moins foncé, plus ou moins livide. Après les variations que produisent l'âge et le clinıat, la crainte 
ou la colère, et les différents degrés de chaleur sont les causes principales des changements qu'on remarque sur la peau, qui prend successivement des nuances jaunâtres, verdâtres ou bleues.

On trouve des caméléons dans tous les climats chauds, tant de l'ancien que du nouveau continent. Les Indiens les gardent dans leurs maisons, pour les délivrer des insectes. Cet animal est très doux et ne cherche jamais à mordre. Il peut vivre près d'un an sans manger, ainsi que les autres lézards. 


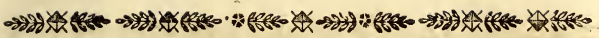

\section{LE BASILIC.}

Ce Lézard, habite l'Amérique méridionale. Aucune espèce n'est aussi facile à distinguer, à cause d'une crète très exhaussée qui s'étend jusqu'au bout de la queue, et d'une sorte de capuchon qui couronne la tête. Il a sóuvent plus d'un mètre de longueur.

Loin de tuer par son regard, comme l'animal fabuleux dont il porte le nom, le Basilic fait plaisir à la vue, lorsqu'animant la solitude des forêts immenses de l'Amérique, il s'élance avec rapidité de branche en branche, ou bien, lorsque, dans une attitude de repos, il témoigne une sorte de satisfaction à ceux qui le regardent, en agitant mollement sa belle crète, el en faisant briller de diverses manières les écailles dont il est paré. 


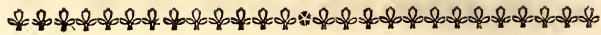

\section{IE CRAPAUD.}

(Planche II, fig. 4.)

Tout est vilain dans cet animal. Sale dans son habitation, dégoûtant par ses labitudes, difforme dans son corps, obscur dans ses couleurs, infect par son haleine, ne se soulevant qu'avec peine, ouvrant, l'orsqu'on l'attaque, une gueule hideuse; n'ayant pour toute puissance que l'opiniâtreté d'un être stupide, et pour arme qu'une liqueur fétide, il ne paraît avoir de bon que l'inslinct de se dérober à tous les yeux, en fuyant la lumière du jour. Sa couleur est ordinairement d'un gris livide, tacheté de brun et de jaunâtre, quelquefois d'un roux sale, qui devient ensuite presque noir. Un grand nombre de verrues, ou plutôt de pustules d'un vert noirâtre ou d'un rouge clair, sert encore à l'enlaidir. Non-seulement il ne peut 
DES ENFANTS.

marcher, mais il ne saute qu'à une très petite hauteur; lorsqu'il se sent pressé, il lance contre ceux qui le poursuivent, une liqueur fétide. Cet animal habite dans les fossés, surtout dans ceux où l'eau croupit depuis long-temps; on le trouve aussi dans les fumiers, dans les caves, dans les antres profonds et dans les forêts où il peut aisément se dérober à la clarté du jour. Il est si vivace, qu'on en a vu qui, percés d'outre en outre par un pieu, ont vécu sept à huit jours exposés à l'ardeur du soleil. Un fait bien constaté prouve qu'un crapaud a vécu plus de trente-six ans, et la manière dont il a passé sa longue vie prouve jusqu'à quel point la domesticité peut influer sur quelque animal que ce soit. Ce crapaud a vécu presque toujours dans une maison où il a été, pour ainsi dire, élevé et apprivoisé. La lumière des bougies avait été long-temps pour lui le signal du moment où il allait recevoir sa nourriture ; aussi, non-seulement il la voyait sans crainte, mais même il la recherchait; il était déjà très gros, lorsqu'il 
104

LE BUFrON

fut remarqué pour la première fois. Sa retraite était un escalier qui se trouvait devant la porte d'une maison. Tous les soirs, au moment où il apercevait de la lumière, il levait les yeux, comme s'il eût attendu qu'on le portât sur une table où il trouvait des insectes, des cloportes et de petits vers. Comme on ne lui avait jamais fait de mal, il ne s'irritait point lorsqu'on le touchait, et devint l'objet d'une curiosité générale, au point que les dames même demandèrent à voir le crapaud familier.

Cet animal aurait vécu plus de temps dans cette espèce de domesticité, si un corbeau, apprivoisé comme lui, ne l'eût attaqué à l'entrée de son trou, et ne lui eût crevé un oeil malgré tous les efforts qu'on fit pour le sauver. 


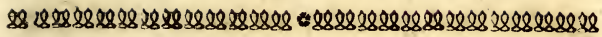

\section{LA GRENOUILLE GOMMUNE.}

(Planche I, fig. 6. )

C'est un grand malheur qu'une ressemblance avec des êtres ignobles! Si nous n'avions jamais vu de crapauds, nous admirerions dans la grenouille une taille légère, une attitude gracieuse, des mouvements prestes et des couleurs agréables, nuancées par un beau vernis.

Lorsque la grenouille est hors de l'eau, loin de se tenir bassement accroupie dans. la fange comme le crapaud, elle porte la tête haute et le corps relevé sur les pattes de devant, toujours prête à s'élancer.

Ses yeux sont entourés d'un cercle couleur d'or. Le dessus de son corps est d'un vert plus ou moins foncé, et le dessous blanc. Trois raies jaunes qui règnent le long du dos, des taches noires qui s'étendent sur tout le dessous du corps, et 
même sur la parlie supérieure à mesure que l'animal grandit, relèvent cet élégant assemblage de couleurs.

Assez difficiles sur la qualité de leur nourriture, les grenouilles ne se nourrissent que d'insectes vivants tels que vers, sangsues, petits limaçons, etc. Quand l'insecte se trouve à leur portée, elles s'élancent sur lui, quelquefois à la hauteur d'un ou de deux pieds, et l'engloutissent dans leur large bouche. Dès que la belle saison est arrivée, on les entend jeter un cri qu'elles répètent pendant assez longtemps , surtout lorsqu'il est nuit. Ce coassement, composé de sons ra uques, devient tout-à-fait désagréable par la continuité, et parce qu'elles se plaisent à se réunir pour le multiplier.

Les œufs que pond la femelle forment une espèce de cordon, à cause de la matière glaireuse dont ils sont enduits. Ces œufs, après un temps plus ou moins long, suivant la température, produisent ce que l'on appelle des têtards, dans lesquels on distingue bientôt la tête, la poitrine, le 
ventre, et une queue dont ils se servent pour se mouvoir. Deux mois après, ces têtards quittent leur enveloppe pour prendre la vraie forme de grenouilles. Comme certaines parties de leur corps fournissent un aliment agréable, on a imaginé plusieurs manières de les pêcher; d'abord avec des filets, à la clarté des flambeaux qui les effraient, puis à la ligne, avec des hameçons qu'on garnit de vers, d'insectes, ou simplement d'un morceau d'étoffe rouge ou couleur de chair. Un râteau à longues dents est encore un moyen que l'on emploie avec succès pour les ame nerà terre. 


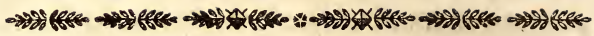

\section{LA ROUSSE.}

(Planche IX, fig. 3.)

Cette grenouille qui habite dans les mêmes pays que la grenouille commune, a le dessus du corps d'un roux obscur, et les cuisses rayées de brun. On l'appelle muette. Elle passe à terre une grande partie de la belle saison, et ne regagne les endroits marécageux que vers la fin de l'automne.

Comme les grenouilles rousses sont très fécondes, et qu'elles pondent depuis six cents jusqu'à onze cents cufs, les petites grenouilles de cette espèce se montrent quelquefois en si grand nombre surtout dans les bois et le terrain humide, que la terre en paraît couverte. Cette multitude, sortant de ses trous lorsqu'il pleut, a donné lieu à deux fables : l'une, qu'il pleuvait des grenouilles, et l'autre, qu'elles s'en allaient aussi promptement qu'elles 
DES ENFANTS.

étaient venues, et qu'elles disparaissaient aux premiers rayons du soleil. Un examen plus sérieux aurait fait découvrir ces grenouilles sous des tas de pierres et autres abris, et on les aurait vues se cacher de nouveau après la pluie, pour se dérober à une lumière trop vive.

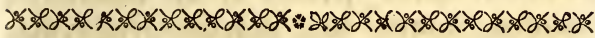

\section{LE DEVIN.}

Ce serpent, qui parvient communément: à la longueur de plus de sept mètres, est le plus grand et le plus fort de tous les serpents. La nature lui a accordé la beauté, le courage et l'industrie : n'ayant point de venin, il combat avec hardiesse, oppose la force à la force, et ne dompte que par sa puissance.

On trouve ce monstrueux animal dans les déserts brûlants de l'Afrique. Sa tête a été comparée, et avec assez de raison, à celles des chiens de chasse, qu'on appelle chiens couchants. Sa queue est très courte 
en proportion de son corps, qui est ordinairement neuf fois aussi long que cette partie, mais elle est très dure et très forte. Sur tout le dessus de son corps se trouvent de belles et grandes taches ovales, qui ont ordinairement deux ou trois pouces de longueur, et autour desquelles l'on voit d'autres taches petites et de différentes formes. Toutes sont placées avec symétrie, et la plupart sont distinguées du fond par des bordures sombres, qui, en imitant des ombres, les détachent et les font ressortir. Ces belles taches présentent les couleurs les plus agréablement variées, et quelquefois les plus vives. Les taches ovales sont ordinairement d'un fauve doré, quelquefois noires ou rouges, et bordées de blanc; les autres sont d'un châtain plus ou moins clair, ou d'un rouge très vif, semé de points noirs ou roux. Le dessous du corps est d'un cendré jaunâtre , marbré ou tacheté le noir. Il y a de quoi frémir en lisant, dans les relations des voyageurs, la manière dont l'énorme serpent Devin s'avance au milieu des herbes hautes 
DES ENFANTS.

et des broussailles, semblable à une longue poutre qu'on remuerait avec vitesse. On aperçoit de loin, par le mouvement des plantes qui s'inclinent sur son passage, l'espèce de sillon que tracent les liverses ondulations de son corps; on voit fuir devant lui les troupeaux de gazelles et d'autres animaux dont il fait sa proie. Le seul moyen de se garantir de sa dent meurtrière, dans ces solitudes immenses, est de mettre le feu aux herbes déjà à demibrulées par l'ardeur du soleil; car le fer ne suffit pas contre ce dangereux ennemi, surtout lorsqu'il est irrité par la faim. En vain voudrait-on lui opposer des fleuves, ou chercher un abri sur des arbres : il nage avec assez de facilité pour traverser des bras de mer, et se roule avec promptitude jusqu'aux cîmes les plus hautes.

Lorsque le devin aperçoit un ennemi dangereux, ce n'est point avec les dents qu'il commence le combat, mais il se précipite avec tant de rapidité sur sa malheureuse victime, l'enveloppe de tant de contours, et lá serre avec tant de force, 
qu'il rend ses armes inutiles, et la fait bientôt expirer sous ses puissants efforts. Si l'animal immolé est trop considérable pour que le Devin puisse l'avaler, malgré la grande ouverture de sa gueule et la facilité qu'il a de l'agrandir, il continue de presser sa proie, et pour la briser avec plus de facilité, il l'entraîne, en se roulant avec elle, auprès d'un gros arbre, dont il renferme le tronc dans ses replis, la place entre l'arbre et son corps, les environne l'un et l'autre de ses nouds vigoureux, et se servant de la tige noueuse, comme d'un levier, il redouble ses efforts, et parvient à comprimer en tous sens le corps de l'animal qu'il a immolé. Après avoir donné à sa proie toute la souplesse qui lui est nécessaire, il continue de la presser, pour l'allonger, et pétrit avec sa salive cet amas de chairs ramollies et d'os concassés. Quelquefois il ne peut en engloutir que la moitié, alors la dernière partie reste à découvert, jusqu'à ce que la première ait été digérée. 


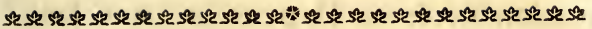

\section{LE SERPENT.}

(Planche I, fig. 9.)

On donne le nom de Serpent à un ordre d'animaux reptiles (1), dont le corps couvert d'écailles est allongé, presque cylindrique et très flexible. A les voir en repos, on croirait qu'ils n'ont pas la faculté de se transporter d'un lieu à un autre; mais la nature leur a fourni des moyens particuliers. Pour changer de place, ils appuient la partie antérieure de leur corps sur la terre, puis ils soulèvent la partie moyenne en avançant la postérieure, et portent en avant la partie antérieure, après avoir abaissé la partie intermédiaire. A l'aide de ces mouvements, l'animal marche et avance sans jambes, comme il nage sans nageoires. Les serpents sont du nombre

(1) Reptiles, animaux qui rampent au lieu de marcher. 
des animaux qui ont le sang froid et la digestion fort lente. Ils peuvent vivre longtemps sans prendre d'aliments, ainsi qu'on l'observe dans les vipères et dans les couleuvres renfermées sans vivres, pendant sept ou huit mois, dans des barils aérés. Combien de fois n'a-t-on pas vu des grenouilles, des souris peu endommagées, dans l'estomac de ces animaux, quoique avalées quelques jours auparavant?

Il y a des serpents dont les petits éclosent dans le ventre de leur mère, et viennent au jour, vivants ; on les appelle vipères.Les serpents de la classe des couleuvres, font des œufs qui éclosent après avoir été pondus. Les premiers sont généralement venimeux, les couleuvres ne le sont pas. Les serpents ovipares ne couvent pas leurs œufs, ils les déposent dans des trous exposés au midi, ou voisins d'un four, ou dans des couches de fumier, etc. Ces œufs éclosent, lorsqu'ils ont été échauffés par l'un de ces moyens; ils n'ont point de coque, mais seulement une membrane flexible. Ces reptiles se dépouillent de leur pre- 
DES ENFANTS.

mière peau, au printemps et en automne. Cette mue s'opère dans l'espace d'une nuit et d'un jour. Leur voix est un sifflement plus ou moins aigu.

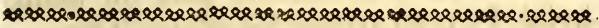

\section{LA VIPERE.}

(Planche II, fig. 6.)

La Vipère est aussi faible et aussi innocente, en apparence, que son venin est dangereux. Sa longueur totale est communément de 60 centimètres. Sa couleur est d'un gris cendré. Sur le dos, s'étend une espèce de chaîne de taches noirâtres, de forme irrégulière. Outre vingt-huit dents à la mâchoire inférieure, , elle a encore, de chaque côté de la mâchoire supérieure, une ou deux, quelquefois trois ou quatre dents longues, crochues et très aiguës, qu'elle peut incliner ou redresser à volonté. Ces dents sont comme un canal par où passe, lorsqu'elle veut mordre, le ve-- 
nin qu'elle tient renfermé dans de petites vessies, au-dessus de la mâchoire supérieure. Les morsures de vipères sont plus dangereuses, suivant la chaleur de la saison et l'état de l'animal plus ou moins irrité. Pour en arrêter les effets, il faut, si l'on n'a pas le courage de couper la partie mordue, la lier tout de suite après l'accident, pour arrêter la circulation du sang. $L a$ vipère a les yeux vifs; et comme si elle sentait la puissance redoutable de son venin, son regard paraît hardi. Quand on l'irrite, elle ouvre la gueule et darde sa langue avec tant de vitesse, qu'on s'imaginerait, à la voir étinceler, qu'elle est de feu. Les vipères peuvent passer plusieurs mois sans manger. On les trouve, dans les grands froids, sous des tas de pierres, dans des trous de vieux murs, réunies plusieurs ensemble et entortillées les unes aux autres. Elles changent de peau au commencement du printemps. Il est rare de les voir attaquer l'homme et les gros animaux, à moins qu'on ne les blesse ou qu'on ne les irrite. Leur vie est si tenace, 
que plusieurs parties de leur corps, tant intérieures qu'extérieures, se meuvent encore, et exercent, pour ainsi dire, leurs fonctions, après qu'elles en ont été séparées. Le cour même palpite longtemps après avoir été arraché ; et les muscles des mâchoires, quoique la tête ne tienne plus au corps, conservent assez de force pour que la gueule s'ouvre et se referme. On trouve des vipères dans presque toutes les contrées de l'ancien continent. Le ci-devant Poitou est l'endroit de la France qui en fournit le plus. Excepté la tête, toutes les parties du corps de cet animal étaient employées autrefois en médecine. Comme ils ne peuvent sauter, ni s'entortiller aussi aisément que la plupart des autres serpents, les paysans emploient, pour les prendre, une petite fourche avec laquelle ils soulèvent leur tête, puis ils les saisissent par la queue et les mettent dans un sac. D'autres leur appuient sur la tête l'extrémité d'un bâton, et les mettent hors d'état de nuire, en leur coupant les dents avec un canif. 


\section{I'ANGUILLE.}

Ce poisson, quoiqu'habitant les eaux, peut vivre quelque temps sur la terre. On prétend même qu'on en voit sortir quelquefois d'un étang, pour chercher d'autres eaux. Les pêcheurs croient qu'elles naissent des perches, ables, éperlans, parce qu'ils ont pris pour des anguilles de petits vers que l'on trouve dans les ouies de ces poissons. La nature suit toujours sa marche dans la multiplication des êtres. L'Anguille est vivipare ; les oeufs qui naissent dans son corps y éclosent, et les petits en sortent vivants. Il ne paraît point que l'anguille multiplie dans les étangs; on est porté à croire qu'elles vont frayer dans la mer, d'où les petites anguilles remontent ensuite dans les eaux douces. Il y a des rivières où elles descendent à la fin de l'été, pour aller à la mer, et en remontent à la fin de l'hiver. L'anguille 
habite toujours le fond des eaux; ce n'est qu'à l'approche des orages qu'el e s'élève jusqu'à la surface de l'eau, pour respirer.

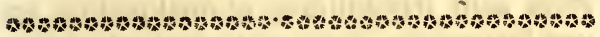

\section{LA GOULEUVRE DES DAMES.}

(Planche VII, fig. 6.)

Ce joli petit animal est aussi intéressant par la délicatesse de ses proportions, que par la légèreté de ses mouvements. Un beau noir et un blanc assez pur sont les seules couleurs qu'il présente; mais elles sont si avantageusement contrastées et si animées par le luisant des écailles, qu'il serait difficile d'imaginer une parure plus agréable. Des anneaux noirs traversent le dessus du corps et de la queue, et en interrompent la blancheur. Ces bandes transversales s'étendent jusqu'aux plaques blanches qui revêtent le dessous du ventre. Leur largeur diminue à mesure qu'elles approchent de dessous du corps, 
et la plupart vont se réunir, sous le ventre, à une raie noirâtre et longitudinale, qui occupe le milieu des grandes plaques. Cette raie ainsi que les bandes transversales sont irrégulières et quelquefois un peu festonnées, mais cette irrégularité ne fait qu'ajouter à l'élégance, en augmentant la variété. Le dessus de la tête présente un mélange grâcieux de noir et de blanc, où cependant le noir domine. Les yeux sont très-petits, mais animés par la couleur noirâtre qui les entoure. La Couleuvre des Dames est si familière, qu'elle n'éprouve pas la moindre crainte, lorsqu'on l'approche. Sa petitesse, son peu de force, l'agrément de ses couleurs, la douceur de ses mouvements et de ses habitudes inspirent un tel intérêt pour elle, que le sexe le plus timide, loin d'en avoir peur, la prend dans ses mains et la ca= resse. 


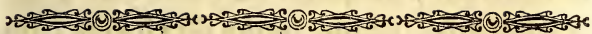

\section{LA GOULEUVRE COMMUNE.}

(Planche V, fig. 5. )

Ce reptile, aussi innocent que la vipère est dangereuse, est très commun en France, surtout dans le midi ; il en peuple les bois et les divers endroits tempérés et humides. On ne l'a encore trouvé ni dans les régions chaudes, ni dans le nord de l'ancien continent, non plus qu'en Amérique.

Le dessus de son corps, depuis le museau jusqu'à l'extrémité de la queue, est noir ou d'une couleur verdâtre très foncée, sur laquelle on voit s'étendre, d'un bout à l'autre, un grand nombre de raies composées de petites taches jaunâtres de diverses figures, les unes allongées, les autres en losanges, etc., et un peu plus grandes vers les côtés que vers le milieu du dos. Le ventre est d'une couleur jaunậtre : chacune des grandes plaques quị 
le couvrent, présente un point noir à ses deux bouts, ce qui forme de chaque côté une rangée symétrique.

Ce joli petit animal parvient ordinairement à la longueur de trois ou quatre pieds. Dans tous les endroits où le froid est rigoureux, il s'enfonce, dès la fin de l'automne, dans les trous souterrains ou dans d'autres creux, où il s'engourdit plus ou moins complétement; lorsque les beaux jours du printemps reparaissent, il sort de sa torpeur, et se dépouille comme les autres serpents.

Cette Couleuvre cherche à fuir, lorsqu'on l'approche. Non-seulement on peut la saisir sans danger, puisqu'elle n'a pas de venin, mais mème sans éprouver d'autre résistance que quelques efforts qu'elle fait pour s'échapper. Bientôt on l'assujétit à prendre les différents mouvements qu'on veut lui faire suivre. Elle se laisse entortiller autour des bras, tourner en différentes positions, sans donner aucun signe de mécontentement ; elle paraît mêrne avoir du plaisir à jouer avec ses maîtres. 


\section{DES ENFANTS.}

Comme sa douceur et son défaut de venin ne sont pas encore aussi bien connus qu'ils devraient l'être, des charlatans se servent de ce serpent, pour faire croire qu'ils ont le privilége de se faire obéir par un animal que leurs admirateurs ne regardent qu'en tremblant. Il faut cependant convenir qu'on a vu des couleuvres, surprises par l'aspect subit de quelqu'un, se redresser avec fierté, et faire entendre un sifflement de colère ; mais dans ce moment même, qu'avait-on à craindre d'un animal sans venin et dont les dents ne peuvent blesser que de petits lézards ? C'est à celte espèce de couleuvre qu'il faut rapporter le fait suivant, attesté par un naturaliste digne de foi. Cet observateur a vu une couleuvre, tellement affectionnée à la maîtresse qui la nourrissait, qu'elle se glissait souvent le long de ses bras, pour la caresser, se cachait sous ses vêtements, venait au moindre signal, reconnaissait jusqu'à sa manière de rire, et se tournait vers elle, lorsqu'elle marchait, comme pour attendre son ordre. 


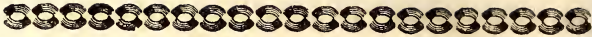

\section{LE REQUIN.}

(Planche VIII, fig. 7. )

Le Requin ou Squale de mer, poisson vorace qui habite les mers des pays chauds, il a jusqu’à six mètres de longueur sur quatre ou cinq mètres de circonférence ; sa gueule est si large qu'il peut avaler un homme entier. Cette affreuse gueule est garnie de plusieurs rangées de dents tranchantes, comme un rasoir. Il n'a point d'écailles,mais sa peau est rude et grenue.

Il s'attache à la suite de navires pour se nourrir des immondices et des cadavres qu'on jette du bord. Tout lui est bon : malheurs au cuisinier qui à mis dessaler un morceau de bœuf a la mer ; ou au matelot qui après avoir lavé ses vêtements les tient plongés dans l'eau attachés à une corde pour les rincer; si le requin passe par là, le matelot ou le cuisinier ne retirent 

PI.VIII

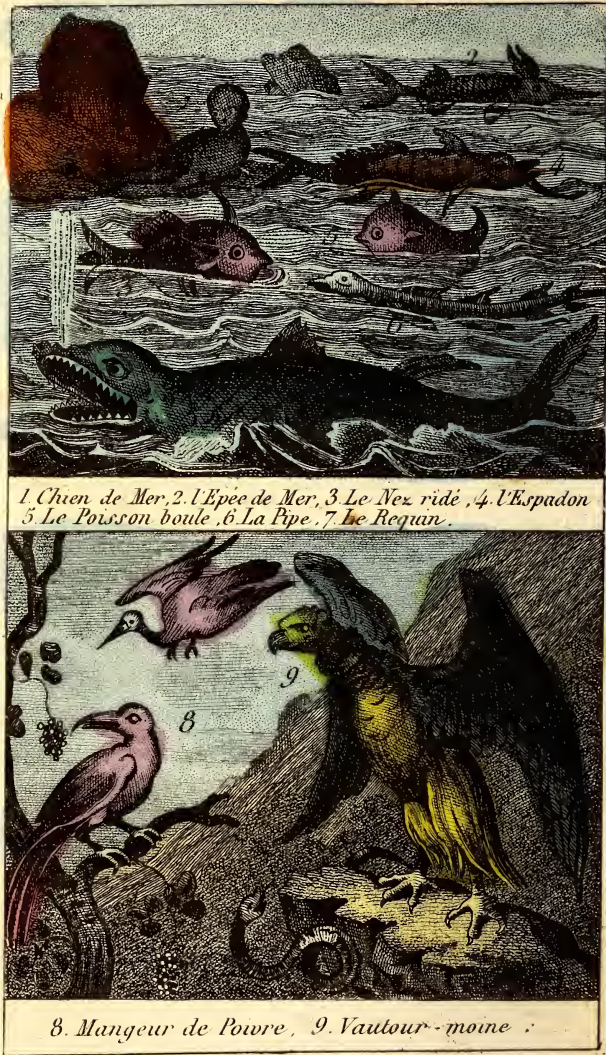


DES ENFANTS.

de la mer qu'une corde proprement coupée, car le requin a avalé, viande et culottes.

Rien n'est plus dangereux que de se baigner dans les parages infestés par les requins. Heureusement la gueule de cet animal étant placé en dessous il doit se retourner sur le dos pour engloutir sa victime, ce qui donne quelquefois le temps au malheureux nageur de regagner sa barque.

Le requin est l'ennemi né des matelot; on le prend à l'aide d'un croc en forme d'hameçon, attaché à une chaîne de fer et amorcé d'un morceau de bœeuf; le jour où l'on fait la capture d'un requin est un jour de fête pour le matelot. On le hisse à bord, on lui coupe la queue et on l'eventre, puis on jette ses dépouilles à la mer, car il n'y a de bon que le foie dont on fait de l'huile.

Sa peau, aussi rude qu'une lime, est employée pour polir les bois ou d'autres substances. On en couvre aussi des étuis de lunetles et autres petits ouvrages de gaînerie. On enchâsse ses dents dans l'argent ; pour 
servir de hochet aux enfants. Le peuple crédule les leur fait porter en amulettes, pour les préserver des maux de dents et de la peur. On en compose encore des poudres dentifrices.

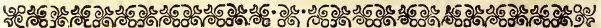

\section{LE NEZ RIDÉ.}

(Planche VIII, fig. 3.)

Ce poisson a la tête aplatie, huit dents à chaque mâchoire, et au-dessus des nageoires de la poitrine, de longs trous pour respirer, situés dans une raie ou gouttière non recouverte : sa peau, qui est comme du parchemin, est recouverte d'écailles. II y en a huit espèces qui toutes tirent leurs noms de leurs excroissances cornues, et qui se trouvent dans l'Océan, entre l'Afrique et l'Amérique. L'un des plus remarquables est le Nez Ridé, qui contracte son nez et sa lèvre supérieure, de manière qu'on lui voit à nu toute la mâchoire d'en haut; sa première mâchoire est comme rayonnante et en forme de corne. 
2

\section{LE PORC-ÉPIC DE MER.}

Ce poisson des Indes occidentales, de différentes formes, rond comme un ballon, se nourrit de coquillages. Les épines dont il est armé, et qu'il baisse et élève à volonté, sont si piquantes, que lorsqu'il est pris à l'hameçon, on ne peut le saisir par aucune partie du corps, jusqu'à ce qu'il soit mort. Sa chair, a le goût du veau; les bourses pleines d'air qu'il a dans le ventre, servent à faire une colle tenace.

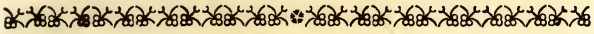

\section{LA PIPE.}

(Planche VIII, fig. 6.)

C'est un poisson long et menu, qui a ordinairement un pied de long, et quelquefois un pied et demi, de la grosseur de deux doigts, et sans écailles. Il se trouve dans les deux Indes. 


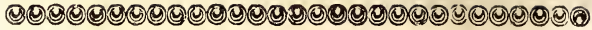

\section{LE POISSON-BOULE.}

(Planche VIII, fig. 5.)

Il se trouve vers le cap de Bonne-Espérance, et dans l'A mérique septentrionale. Au reste, il y en a de deux espèces; le Porc-Epic de mer qui est de figure ovale, et le Poisson-Boule qui est tout rond, à peu de chose près, et de la grosseur d'un gros ballon à jouer. 


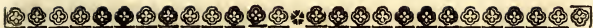

\section{L'ESPADON.}

(Planche VIII, fig. 4. )

Espadon, poisson à scie, épée de mer, héron de mer, poisson empereur. C'est une espèce de baleine. Sa scie est très dure et très forte, les piquants plats et tranchants. L'espadon cherche et poursuit la baleine. Celle-ci d'un coup de queue l'écraserait; mais l'agilité de l'agresseur lui assure la victoire. Il s'élance sur son ennemie pour la percer. Ce combat cruel, qui se passe au sein de la mer, est annoncé aux voyageurs effrayés par le fracas épouvantable que fait la queue de la baleine, et par le sang qui s'élève en bouillonnant à la surface des flots. Les nègres respectent ce poisson. Ils mettent sa scie au rang de leurs dieux. 


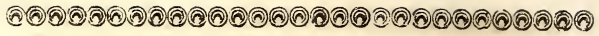

\section{L'ÉPÉ DE MER.}

(Planche VIII, fig. 2.)

On l'appelle aussi poisson empereur. Ce poisson porte à la tête une arme osseuse qui a la forme d'une lame d'épée longue de quatre, cinq à six pieds, et large d'un demi-pied, qui lui sert pour l'attaque et pour la défense; il se nourrit de plantes marines et d'animaux marins. Il se trouve surtout dans les mers du Nord, à la suite des baleines, dont il est un ennemi mortel et dangereux, puisqu'il leur enlève quelquefois des pièces considérab!es de chair, et qu'il les tue à coups de poignard. Souvent les Épées de Mer s'assemblent en nombre pour attaquer la baleine, et, quelque grosse qu'elle soit, ils en viennent à bout; ils trouvent même le moyen de lui entrer dans la gueule et de lui couper la langue, qui n'est 
DES ENFANTS.

presque qu'une énorme pièce de lard, qu'ils mangent avidement. C'est un animal fort audacieux, qui se révolte même contre l'homme et qui s'en fait craindre. On le prend au harpon comme la baleine. Il s'en trouve de fort gros, qui ont dix-huit à vingt pieds de long, et pèsent deux cents livres : sa chair est bonne à manger. 


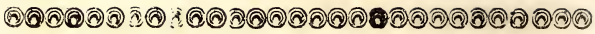

\section{LE PHOQUE.}

( Planche VIII, fig. 1)

Ce vivipare, auquel on donne encore le nom de veau marin, se trouve dans les mers du Nord et dans les lacs de ces contrées froides, tant en Amérique qu'en Europe et en Asie, comme en Islande, Groënland, Spitzberg, Kamtschatka, dans la mer Baltique, sur les côtes de Norwége, de Hollande, d'Angleterre, de France, etc. Le Chien de Mer a depuis un mètre et demi jusqu'à deux de longueur et de deux jusqu'à quatre de haut. Il a la tête grosse, de longues moustaches de poils raides, disposées comme celles du chat, avec de semblables soies sur le nez et sur les yeux, avec quelque différence selon les espèces ; les yeux gros, les oreilles sans bouts ou pendants; la queue courte, les jambes et les pieds d'une figure toute particulière.; 
enfin tout le corps revêtu de poils courts et raides , tantôt d'un gris blanc, tantôt d'un gris noir , ou bigarrés de noir et de blanc. Ces animaux ne mangent presque que du poisson et surtout des harengs, et ils vivent environ vingt à vingt-cinq ans : la femelle fait tous les ans une portée d'un ou deux petits. Quant à la forme tout à fait singulière des pattes du phoque elle est telle qu'il ne s'en peut servir, que pour nager. Sur terre, il est obligé de se traîner presque comme un vermisseau , ou de ramper avec ses pattes de devant. A proprement parler, il n'a point de jambes, mais seulement quelque chose d'approchant ; les pattes de devant sont un peu plus longues que celles de derrière, tortues, courbées en en arrière, munies de cinq doigts, avec de gros ongles pointus, presque semblables à celles des oies ou plutôt des taupes; celles de derrière sont aussi tortues, palmées et armées d'ongles, mais tellement recourbées en arrière, qu'elles semblent se confondre avec sa queue 
134

fourchue. On croirait encore qu'un animal si peu fait pour marcher, soit sur la glace, la terre ou le sable, ne saurait vivre que dans la mer : cependant il ne laisse pas de passer hors de l'eau, c'est à dire sur la terre ou sur la glace, la plus grande partie de l'été, n'allant à l'eau que pour chercher de la proie : sa femelle met bas à terre, et y élève même ses petits. A l'aide de ses ongles crochus, il peut grimper sur le haut des rochers et des montagnes de glaces, où il se repose et dort : puis, quand il veut descendre, il se lance à l'eau du sommet de ces hauteurs, ou s'y laisse tomber. Malgré la conformation de ses jambes, il ne laisse pas de se traîner en rampant sur la glace assez vîte pour échapper quelquefois au groënlandais. Au reste, les peuples de ces régions en tirent beaucoup d'avantages; ils en mangent la chair et la graisse, et se vêtissent de la peau : les Esquimaux en font de même, aussi bien que d'autres nations sauvages de ces contrées. Cette 
DES ENFANTS.

chair est rouge, tendre, succulente, grasse, et se mange tant fraîche que fumée.

On mange de même le lard, qui a deux ou trois doigts d'épais, ou l'on en brûle une partie dans les lampes en guise d'huile. Enfin, l'on emploie la peau à faire des habits, des camisoles, des bonnets, des culottes, des bottes, des souliers, des courroies, des cordes, des outres, et même à faire de petits canots noinmés cayaques, ou du moins à les revêtir par dehors et par dedans : ces peuples en recouvreut aussi leurs cabanes d'été, et en vendent une infinité aux Européens qui, à leur tour, s'en servent pour recouvrir des coffres et, des malles , à faire des garnitures de bonnets, des tabatières. Les phoques sont pour les peuples indigents du Nord, une ressource si nécessaire, que s’ils en étaient privés, il faudrait qu'ils périssent de faim et de froid. La plupart du temps on les surprend endormis sur les glaces, et l'on a le temps d'en tuer des centaines, avant 
que les autres songent à s'éveiller, tant ils dorment profondément sans souci, sans inquiétude, sans avoir même le soin de se garder en plaçant des sentinelles. Cependant ils mordent cruellement quand ils peuvent attraper les jambes ou les mains de quelqu'un ; mais on ne les laisse pas approcher de si près, de façon qu'ils sont réduits à se jeter sur les bâtons qu'ils coupent souvent en deux, quoique gros comme le bras : du reste ils font un bruit affreux, les gros aboient comme des chiens enroués, les jeunes miaulent comme des chats. II suffit de leur appliquer quelques coups sur le nez pour les faire tomber morts ou à demi-morts, et sur-le-champ on les égorge, on les écorche, on leur coupe le lard, on en remplit des tonnes que l'on emporte pour le faire fondre, et en faire de l'huile de poisson. Ils ont la vie si dure, que souvent lorsqu'ils sont déjà écorchés tout à fait ou à demi, ou avec le crâne brisé, ils se débattent encore, font des sauts considérables et cherchent à mordre. 


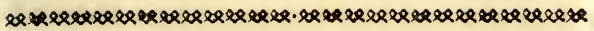

\title{
LE LÉZARD VOLANT.
}

\author{
(Planche V, fig. 2.)
}

C'est un lézard qui a des espèces d'ailes à peu près comme les chauves-souris, au moyen desquelles il peut sauter lestement d'un arbre sur un autre, et de terre sur les arbres, mais non pas voler aussi librement que les oiseaux, et se mouvoir comme eux dans l'atmosphère ; ce qui a suffi cependant pour lui faire donner le nom de Lézard Volant. Il se trouve dans l'Afrique et dans les Indes, n'a tout au plus que la longueur du doigt, ressemble presqu'en tout aux lézards ordinaires, et mange des mouches et d'autres petits insectes. 


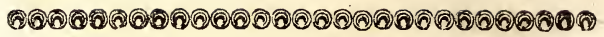

\section{LE PAON.}

(Planche VI , fig. 4.)

Ce bel oiseau joint à l'élégance de sa taille et à la richesse de son pennage, une démarche grave, majestueuse. Fier de sa brillante parure, il porte sa tête avec dignité, et lorsqu'il voit les yeux tournés sur lui, il semble enfler d'orgueil ; c'est alors qu'il étale avec pompe, en forme d'éventail, les plumes de sa queue, dont les compartiments d'or et d'azur, les yeux, les nuances frappées des rayons du soleil, font un spectacle éblouissant. C'est sous cet aspect éclatant qu'il se présente aux yeux de sa femelle pour la séduire. Celle-ci n'est pas à beaucoup près si riche en couleurs. Ces oiseaux, dit-on, nous viennent des Indes. Ils étaient si rares autrefois, qu'on n'en voyait que chez des princes. Ils se sont bien naturalisé 
DES ENFANTS.

dans nos climats. Devenus nos oiseaux domestiques, ils sont comme les oies, des sentinelles vigilantes. Leur cri triste et désagréable fait oublier la beauté de leurs plumage. Le Paon vit d'orge et d'autres graines. Les paons blancs sont communs dans les pays du Nord. Celui du Japon est d'une rare beauté. 
0000000000000000000000000000

\section{LE GOQ D'INDE.}

(Planche VII , fig. 2.)

Cet oiseau transporté des Indes occidentales, s'est naturalisé dans nos climats, et supporte assez bien le froid et les frimats, surtout l'espèce à plumes grisâtres. C'est dans l'hiver qu'il engraisse. Pour les rendre plus robustes et endurcis au froid, on assure qu'il faut les plonger dans l'eau à l'instant de leur naissance. La femelle nommée dinde ou poule d'Inde, pond à la fin de l'hiver et à la fin de l'été , quinze œufs chaque fois, et peut en couver vingt-cing à la fois. Les dindonneaux sont délicats à élever. Leur première nourriture consiste dans du pain avec du vin ou du cidre. Plus forts, on leur donne une pâte de farine et d'orties hachées. Au bout d'un mois ils sont en état d'aller aux champs. Le dindon à be- 


\section{DES ENFANTS.}

soin de boire, surtout dans les grandes chaleurs. On le voit quelquefois se pavaner en étalant sa queue en forme de roue, d'où est venu le proverbe trivial, fier comme un coq d'Inde. On trouve dans l'Amérique Septentrionale des dindons à l'état sauvage auxquels on fait la chasse. Lorsqu'ils sont poursuivis de trop près, ils se perchent sur les arbres voisins. S’ils échappent à la gueule du chien, ils ne sont pas à l'abri du fusil du chasseur, qui peut les tuer l'un après l'autre sans qu'ils s'envolent. Le plumage de cet oiseau est assez beau. Les naturels $d u$ pays prennent les longues plumes de la queue pour faire des parasols et des éventails. Les petites plumes sont employées à faires des mantes d'hiver. 


\title{
IE COQ DOMTSTIQUE.
}

\author{
(Planche VII, fig. 1.)
}

Sa contenance est fière, sa démarche grave, son naturel hardi, courageux, son tempérament chaud, vigoureux. Son chant est l'horloge de la campagne jour et nuit. Sa voix se tire du bas de la trachée-artère. La poule est sa femelle. Au milieu de son sérail, tantôt en amant doux , complaisant, attentif, il est aux petits soins, avertit les poules du danger, les appelle pour partager avec lui sa bonne fortune, pousse même la galanterie jusqu'à la leur abandonner tout entière; tantôt c'est un souverain jaloux qui ne souffre pas la présence d'un rival. Si l'on contrefait le chant du coq, il est inquiet, en alarme, rassemble ses poules, veille sur elles avec assiduité. Le combat des coqs est le spectacle chéri des Chinois 
PI VII

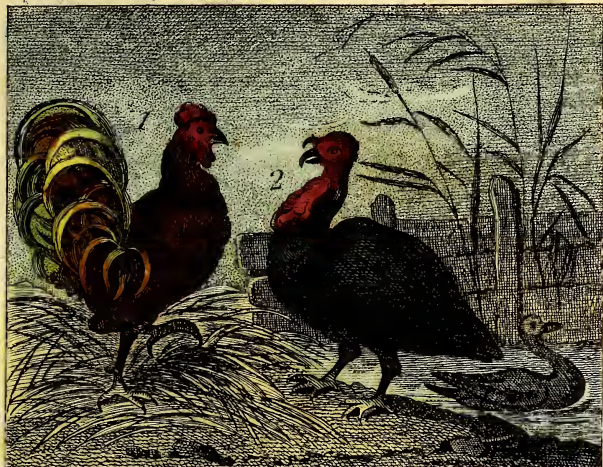
Wro

Vo1. Coq domestique. 2: Coq d'lute..

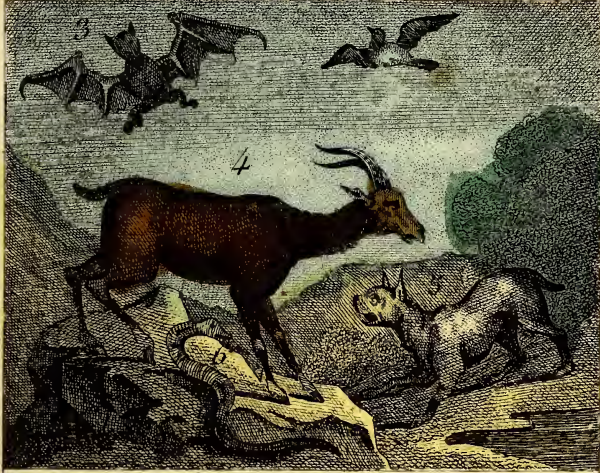
3. Chanve Souris, 4 Chamois, 5Lymx.6Coulciure des Dames. 

et des Indiens. En Angleterre, ces sortes de combats occasionnent un grand concours de spectateurs. Il s'y fait de fortes gageures. On a vu de ces coqs combattre courageusement jusqu'à la mort, plutôt que de survivre à une hontelise défaite. Les Anglais ont une espèce de coqs appelés de Vendhover, qu'ils dressent à la chasse comrne les oiseaux de proie. Le coq de Hambourg, aussi nommé culotle de velours, est une très-belle espèce. 0 n voit quelquefois dans les cabinets des coqs monstreux par leur forme singulière. La corne qu'on remarque sur la tête de quelques-uns, n'est pas toujours naturelle, c'est le produit d'un petit artifice, qui consiste à couper la crête du jeune coq à un travers de doigt des os du crâne, et d'insérer dans cette ouverture un petil ergot de poulet. Cette espèce de greffe réussit à merveille en peu de temps. Le coq de Bentham est si brave, qu'il se bat contre les chats et les chiens. Le coq des bois ou de bruyère est un animal très-paisible. II ne vit que de fruits et d'oufs de fourmis 
144 LE BUFFON

Libre, indépendant, il aime les lieux écartés, un peu marécageux, affectionne spécialement un pin ou un chêne qu'il ne quitte guère. Il y trouve sa retraite et sa nourriture. 


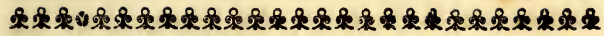

\section{LE POISSON VOLANT.}

II a les nageoires pectorales d'une grandeur extraordinaire, ce qui lui donne le moyen de s'en servir comme d'ailes pour s'élancer hors de l'eau, et voler dans l'air; cependant, dès que ces ailes cessent d'être humides, il est obligé de replonger malgré lui, sauf à lui de ressortir quand il a mouillé ses nageoires volantes. Mais ce u'est point par goût, ni par plaisir qu'il quilte quelquefois l'élément humide ; il faut qu'il se voie poursuivi de trop près par ses ennemis qui sont en grand nombre. Dans la mer Méditerranée, dans les mers des Indes, de la Chine, de l'Amérique, vers le cap de Bonne-Espérance, on voit quelquefois plusieurs centaines de poissons volants, s'élancer à la fois hors des eaux, voltiger quelque temps çà et là, puis retomber daus la mer. Mais ils ne fuient un danger 
que pour tomber dans un autre; ils ont des ennemis partout, les hommes et les oiseaux de proie les attendent et fondent sur eux au sortir de la mer, et à leur rentrée, ils tombent dans la gueule des poissons voraces qui ont suivi leur vol et les guettent aussi. Ils ont communément 50 centimètres de long, et 20 centimètres de large. Mais il y en a de plusieurs espèces ; celui dont il est question, est le Coq de Mer, qui a la tête grosse et armée d'un casque, et trois allonges en forme de doigts au poitrail ; le coq cuirassé, a le corps en forme de bouclier, et un museau fourchu, le roucouleur, quand il est pris, imite le chant du pigeon ; le coucou de mer, imite aussi le chant de l'oiseau de ce nom; le flumbeau de mer, a le dedans de la bouche du plus beau rouge, et, quand il l'ouvre pendant la nuit il donne une vive lumière, elc. 
- 


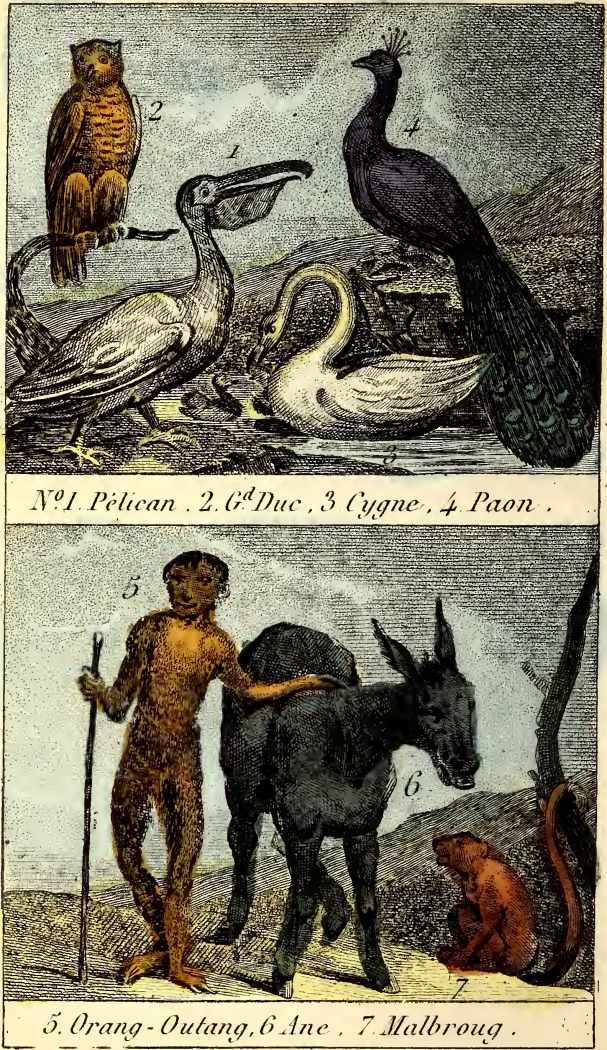




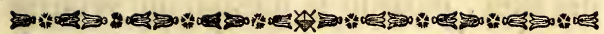

\section{LE PÉLIGAN.}

(Planche VI, fig. 1.)

Cet oiseau, appelé aussi Onocrotale, habite l'Afrique el l'Amérique. Triste, mélancolique, lent à se remuer, à l'aide de ses grandes ailes il s'élève dans les airs, au point de ne pas paraître plus gros qu'une hirondelle. Sa voix imite celle de l'àne. On l'apprivoise aisément. L'empereur Maximilien en avait un qui l'accompagnait même à l'armée. Ce Pélican a vécu 80 ans. Le sommeil et la pêche partagent la vie de cet oiseau paresseux. Il passe presque tout le jour à dormir, perché sur une branche d'arbres, la tête appuyée sur son long et large bec, qui porte sur d'autres branches; éveillé par le besoin, il prend son essor et vole très-haut. S'il aperçoit du poisson vers le bord des rivières et de la mer, il tombe à corps 
perdu. Ce mouvement, joint à l'agitation des ailes, étourdit le poisson qui se laisse prendre. La pression du demi-bec supérieur fait élargir les deux branches du demi-bec inférieur. Le poisson est reçu dans une large poche que la nature a placée sous la gorge du pélican. C'est dans ce havresac que l'animal fait sa provision de vivres pour lui et ses petits. La femelle pond quatre ou cinq œufs. La chair du pélican est dure et de mauvais goût. La forme du bec de cet oiseau est surtout digne d'attention. Le pélican qui parut à Paris en 1750 , avait un bec si large, que la tête d'un homme y entrait aisément. 


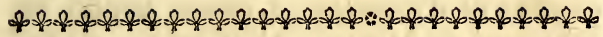

\section{LA HUPPE.}

(Planche IV, fig. 5. )

Cet oiseau, commun en Alsace et en quelques endroits de l'Europe, porte sur la tête une huppe qu'il lève et baisse à volonté. Il habite le fond des bois, se nourrit de chenilles, de vers, de scarabées, fait son nid dans le creux des árbres, y pond quatre œufs, et cherche à l'approche de l'hiver un climat plus chaud. La Huppe marche de mauvaise grâce, et pose souvent à terre. Son vol est bas et léger. Son cris'entend de loin. Elle est peu farouche, facile à apprivoiser. Devenue plus familière, elle fait dans l'intérieur des maisons la chasse aux mouches et aux souris. Elle aime le feu, se couche à terre devant le foyer, étend ses ailes et fait jouer sa crète. Sa chair n'est pas de bon goût. La huppe des montagnes est un oiseau soli- 
taire qui se nourrit de cigales, de grenouilles et d'insectes. L'oiseau huppé ou couronné du Mexique n'est qu'une espèce de huppe. 


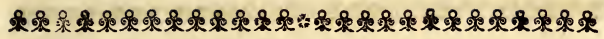

\title{
L'AIGLE NOIR COMMUN.
}

\author{
(Planche IV , fig. 4.)
}

L'aigle noir commun, beaucoup plus petit que l'aigle doré, se trouve en Europe et dans l'Amérique septentrionale, où il fait sa pâture des lièvres, des oiseaux, des poissons, des serpents; il se repaît sur le sommet des grands arbres situés au bord des fleuves, et y élève tous les ans deux ou trois petits, qu'il garde avec lui jusqu'à ce qu'ils aient appris le métier, à l'effet de quoi il ne manque pas de les mener assidûment à la chasse. 
152

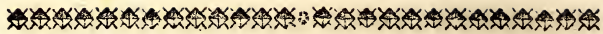

\section{LE VAUTOUR MOINE.}

(Planche VIII, fig. 9.)

On compte jusqu'à onze espèces différentes de ces oiseaux de proie. On en voit dans presque toutes les parties du monde. Ils habitent de préférence les montagnes. Leur caraclère féroce et carnassier se reconnaît à la forme de leurs ongles acérés. Is font leurs nids dans les lieux solitaires, sur les arbres les plus élevés des forêts, poursuivent leur proie au vol et à la course, se nourrissent de sang et de carnage.

Le roi des vautours est le plus beau de tous, il est de la grosseur d'un aigle, a la tête chauve, le cou de même, avec un collier au bas, formé par de longues plumes grises; il a le poitrail gris, le dos et les ailes d'un blanc rougeâtre; le bec, le cou, les jambes et les doigts sont ronges. II ne 
DES ENFANTS.

153

se trouve que dans l'Amérique méridionale. On l'a aussi appelé Vautour Moine, parce que son collier est assez ample pour qu'il y puisse retirer son cou et une partie de sa tête, qui semble alors être dans un capuchon. 


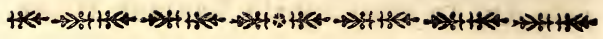

\section{LE MOYEN DUG.}

(Planche VI, fig. 2.)

Oiseau de proie qui ne vole que la nuit. On en distingue trois espèces, le grand duc, le moyen Duc et le petit duc. Le premier, appelé aussi chat-huant, à cause de son cri plaintif, est l'ennemi des corneilles; il leur fait la chasse la nuit, adroitement et sans bruit, ainsi qu'aux petits quadrupèdes et aux oiseaux. Les rochers, les sombres cavernes des montagnes, les édifices ruinés, les toits des greniers, les creux des arbres forment sa résidence ordinaire; il y pond et couve ses œufs, il y élève ses petits : le moyen duc, ou chathuant cornu ou hibou cornu ainsi nommé à cause de ses oreilles, est aussi un grand chasseur. Le petit duc ne diffère du grand que par sa petitesse ; du reste, mêmes ha- 
DES ENFANTS.

bitudes, mêmes inclinations. En Italie, l'on s'en sert pour attirer les oiseaux qui se rendent en foule sur les arbres voisins, et lui font la guerre, ce qui procure la faculté de les tirer et de les prendre, soit au filet, soit à la glu. 


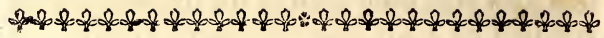

\section{LE BEG GROISÉ.}

Cet oiseau singulier n'est pas plus gros que l'alouetle; son plumage est d'un gris rougeâtre, et celui de la femelle d'un gris jaunâtre. Ce qui le distingue de tous les autres oiseaux, c'est la forme de son bec, dont les bouts sont courbés en croix ou en sens contraire, forme dont il tire parti pour tirer les amandes des pommes de pin et de sapin, dcnt il est très friand. Aussi se tient-il dans les bois de sapins, où il fait son nid sur les plus épais, avec de la mousse et de petits branchages qu'il colle ensemble avec la résine de ces arbres, et qu'il assujétit avec la même matière, de façon que les vents ne peuvent le déranger. Il chante asse\% bien, et imite les manières du perroquet quand on le tient en cage. 


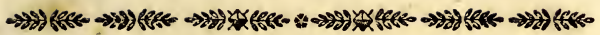

\section{LE CASOAR.}

Cet oiseau est plus petit que l'autruche, mais néanmoins fort grand. Il est noir, et a sur la tête une espèce de coiffe ou de casque osseux , recouvert d'une peau brune, une espèce de collier, entremêlé de rouge et de bleu, et trois doigts aux pieds. On le trouve dans les îles de Banda, de Java et de Sumatra. Il mange tout ce que mange l'autruche, et pond des œufs d'un gris verdâtre, garnis de mamelons verts , et qui ne sont pas si gros que ceux de l'autruche, mais plus longs, Il manque de queue; son plumage ressemble plutơt à des poils qu'à des plumes. Il ne peut faire aucun usage de ses ailes, mais il court très vite. 


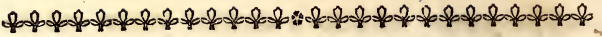

\section{LA GIGOGNE.}

(Planche II, fig. 3.)

Elle fait son aire à découvert, sur le haut des tours, des grands arbres, des églises et des autres édifices: élevés. La Cigogne est à peu près de la grosseur de l'oie; son plumage est blanc, à l'exception d'un peu de noir à la queue et aux ailes. Elle a les jambes fort longues, de même que le bec, et rôde sans cesse dans les marais, où elle prend des serpents, des poissons, des grenouilles, et toutes sortes d'autres petits animaux. C'est un oiseau de passage, dont les pays chauds sont la patrie, mais qui vient visiter les nôtres au printemps, fait sa ponte chez nous, et s'en retourne en septembre avec ses petits déjà forts. 
Comme la cigogne ne fait point de dommage, et au contraire, sert à détruire les animaux nuisibles, tels que les serpents, les scorpions, on a pour elle une sorte de vénération. Les habitants de la campagne s'imaginent mème que les cigognes portent bonheur à la maison sur laquelle elles s'arrêtent ; de sorte qu'ils regardent comme un crime de leur faire du mal. On va même jusqu'à leur préparer des nids sur le haut des toits, et l'on a grand soin de les tenir en bon état pour les y attirer d'une année à l'autre. Et en effet, quand les cigognes reviennent au printemps, chacune cherche son ancien nid, et si elle le retrouve, surtout en bon état, elle ne fait que le nettoyer, puis elle y fait sa ponte. Mais si le nid ne subsiste plus, ou s'il n'est plus en état de lui servir, elle va dans le premier bois prochain, et ramasse de menus branchages souples, dont elle s'en construit un à neuf. Il y a une espèce de cigogne noire, qui est un peu plus petite que la blanche, et ne se trouve qu'en Europe dans les forêts épaisses, au voisinage 
160

LE BUPFON

des marais, où elle cherche la même pâture que l'autre. Klein rapporte que l'on pêcha un jour dans la mer Baltique et dans les mers du Nord, des cigognes qui semblaient être mortes, mais qui ayant été portées dans un endroit chaud, se trouvèrent en pleine vie, et mangèrent avidement ce qu'on leur jeta. 
0000000000000000000000000000

\section{L'OUTARDE.}

L'Outarde est de la grosseur de l'oie. Ces oiseaux vivent en troupe pendant l'hiver, se nourrissent de grains, de fruits et d'insectes. Lorsquils sont à terre, en bandes, il y a toujours un qui fait senti. nelle. Du plus loin qu'il aperçoit quelqu'un, il avertit les autres par un cri. La troupe s'élève de terre difficilement. On en attrape souvent avec des lévriers, qui les saissent quelquefois à moitié élevés dans leur vol. La femelle pond sur terre deux œufs blancs, marqués de deux taches rouges aux gros bouts. On élève des Outardes dans les basses cours. Leur chair est assez bonne. 


\title{
LE MANGEUR DE POIVRE.
}

\author{
(Planclie VIII, fig. 8.)
}

Cet oiseau a le bec d'une grosseur extraordinaire, fort épais à la base, et s'amincissant peu à peu vers la pointe qui est courbe et aiguë, creux en dedans et dentelé, quoique l'oiseau soit à peine de la grosseur d'un pigeon. Il se trouve dans le Brésil et se nourrit des fruits du poivrier.

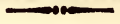




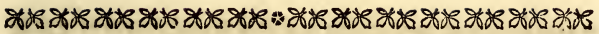

\section{OISEAU de PARAdis.}

\section{(Planche IX, fig. 2.)}

Cet oiseau est intéressant par sa forme et la beauté de son plumage. On le trouve aux îles Moluques, aux Indes. Il vole avec la vivacité de l'hirondelle; aussi l'a-t-on nommé Hirondelle de Ternate. Ces oiseaux, amis entre eux, volent en troupe. On prétend que, sujets dociles, on les voit suivre leur roi dans son vol; toutes leurs démarches sont réglées sur la sienne. Si un chasseur le tue, il se rend presque maître de la troupe entière. Elle ne fuit plus, et périt sous les traits qu'on lui lance. On voit dans les cabinets beaucoup de ces oiseaux qui n'ont point de pattes; les Indiens les coupent et font avec ces oiseaux desséchés, tels qu'on les voit, des éventails ou des panaches dont ils ornent leurs casques. 


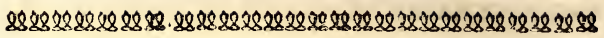

\section{IE CIIAROINERET.}

Ce petit oiseau, impatient et vif, a les caprices qui trop souvent accompagnent le talent. Son plumage varié est d'un bel effet, et on ne peut lui refuser un rang distingué parmi les musiciens champêtres. On l'élève souvent avec les serins, mais il se fait un plaisir malin de troubler la paix de leur ménage. Il se nourrit de chenevis et de plantes à duvet. Il se plaît surtout à éplucher les aigrettes de chardon, ce qui lui a fait donner le nom qu'il porte. C'est daus les vergers qu'il construit son nid. Les matériaux de ce petit édifice sont des mousses, des lichens, des aigrettes de plantes composées. La femelle fait deux pontes par an. Malgré son caractère léger et frivole, on apprivoise le Chardonneret , et on lui apprend à siffler ou à parler. Sa tête est d'un beau rouge; il a une plaque jaune sur les ailes. 


\section{IE MOINEAU.}

Il a le corps mélangé de gris et de noir, et sur l'aile une raie blanche ; parasite aussi vorace qu'incommode, il ne quilte pas nus habitations et préfère même les villes aux campagnes. Il ramasse le grain, le pain, tout lui est bon. En vain cherche-ton à se débarasser d'un hôte si incommode : si on détruit son nid, il en a bientôt construit un autre; si on brise ses œufs, la femelle en pond aussitôt de nouveaux. Trop effronté pour se piquer des rebuts qu'il éprouve, trop rusé pour se laisser prendre aux pièges qu'on lui tend, il est impossible de s'en défuire. Souvent il fait dans les trous des vieux murs, un nid découvert; mais sil le place sur un arbre, il y ajoute une calotte pour le défendre de la pluie. Il y a plusieurs pays où la tête de ce petit voleur est mise à prix ; les moineaux se réunissent souvent en troupe nombreuse. 


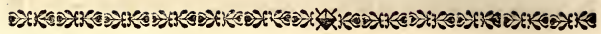

\section{L'HIRONDELLE.}

(Planche II, fig. 1.)

Cet oiseau est noir et marqué d'une tache blanche sur les ailes : il est très commun. Il fait dans nos cheminées, et jusque dans l'intérieur de nos maisons, un nid fortement maçonné avec de la terre mêlée d'herbe et de bourre. Vers la mauvaise saison, les Hirondelles se réunissent et vont chercher ensemble des climats plus doux. L'hirondelle rase la terre en volant, quand il doit pleuvoir, pour saisir les petits insectes dont elle nous débarrasse. Ceux qui la détruisent joignent donc l'injustice à la cruauté. 


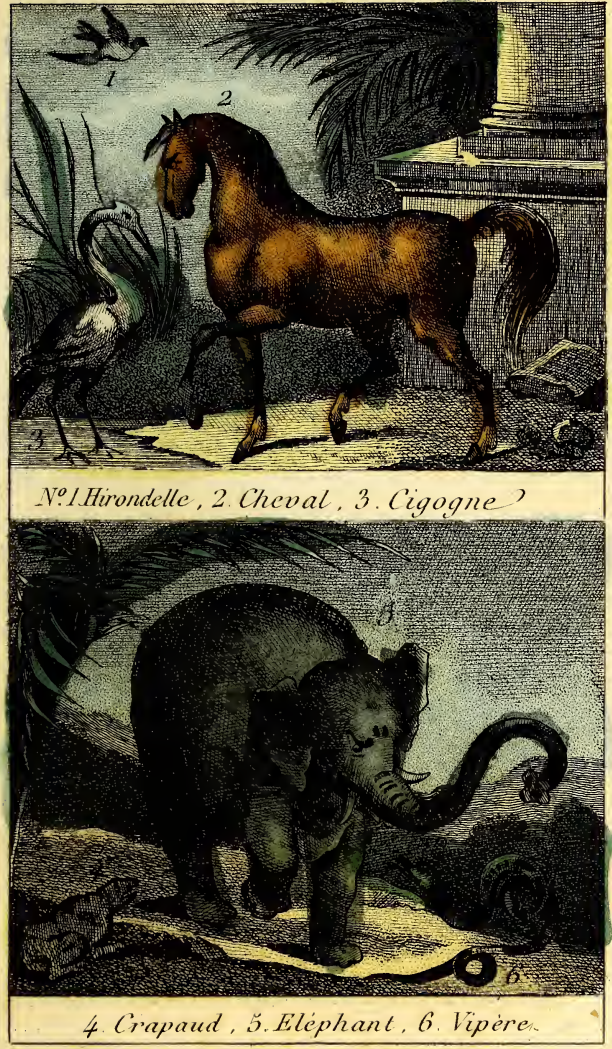





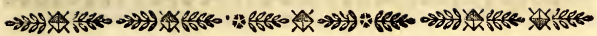

\section{LE ROSSIGNOL.}

Cet oiseau à plumage roussâtre, dont le corps est petit et le bec allongé, a le gosier d'un jaune orangé. L'étendue, la variété et la volubilité de son ramage, l'ont rendu justement célèbre. C'est au printemps qu'il chante le mieux. Sa femelle se fait un nid dans les broussailles. Dès que ses petits sont éclos, le mâle suspend ses chants et ne s'occupe plus que de partager avec elle les soins de les nourrir. Il les instruit ensuite dans son art, et ils deviennent bientôt aussi habiles que leur maître. C'est surtout la nuit dans les bois solitaires et sombres, que le Rossignol aime à faire entendre ses chants , qui font le charme des âmes sensibles et mélancoliques. On le prend au miroir et au filet ; sa chair est bonne à manger. 


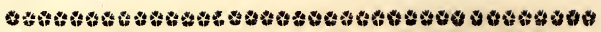

\section{LA FAUVETTE.}

Son plumage, mêlé de gris et de roussâtre, n'a rien de remarquable, mais si elle r'a pas la beauté du rossignol, elle l'égale presque par son ramage, et elle y joint une aimable vivacité. Elle niche ordinaireinent dans les champs de légumes, et elle prend le plus grand soin de ses petits.

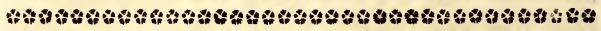

\section{LE ROITELET.}

C'est le plus petit et le plus joli des oiseaux que nous ayons en France, sa couleur est brunâtre; une tache aurore qu'il porte sur le front lui a fait donner son nom, mais 'il peut abdiquer aisément son titre; cette tache na nullement la forme d'une couronne : il se nourrit de très petits insectes et de graines. Sa vivacité est extrème, et il est dans un mouvement continuel. 


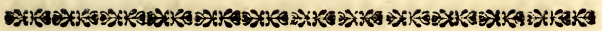

\section{L'ALOUETTE.}

Ce passereau a le corps rousseâtre , les pattes et le bec noirs, la langue fourchue, On l'élève dans des cages à cause de sa facilité à imiter le chant des autres oiseaux, elle s'apprivoise aisément. La femelle cache son nid, et elle a pour ses petits des soins extrêmes. Le vol de l'Alouette est remarquable. Elle s'éléve à plusieurs reprises, toujours perpendiculairement, à perte de vue, et elle ne cesse pendant ce temps-là de chanter. C'est l'alouette que l'on chasse et que l'on vend pour la table, sous le nom de Mauviette. 


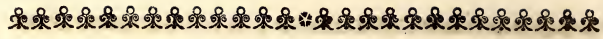

\section{PIGEON. \\ (Planche I, fig. 3.)}

Les narines de cet oiseau sont à demicouvertes d'une membrane molle et gonflée. Le corps est ordinairement cendré. Sa queue blanche est rayée de noir à son extrémité. On connaît un grand nombre de variétés de cette espèce qui diffèrent beaucoup les unes des autres. En général le Pigeon aime la société ; c'est le symbole de l'amitié constante et de l'amour fidèle. La femelle pond deux oufs qu'elle couve pendant le jour; le mâle vienı prendre sa place vers le soir pour lui donner quelque repos. Si le retour de l'un deux a trop tardé, l'autre alarmé par sa tendresse va le chercher. Quand les pigeonneaux sont éclos, le mâle dégorge la nourriture qu'il apporte dans le bec de la colombe, et elle la transmet de même à ses petits. On élève les pigeons dans 
DES ENFANTS.

des volières fermées appelées colombiers. Leur chair est excellente, et leur fiente fer- . tilise la terre.

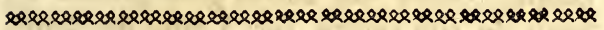

\section{LE GYGNE}

(Planche VI, fig. 3.)

Il est d'une blancheur éclatante, et son bec est d'un beau noir ; il fait l'ornement de nos bassins et de nos canaux, où il se promène majestueusemeut en allongeant et retirant son long cou, qui forme différents replis pour saisir les petits poissons, les vers et les insectes aquatiques. On lui construit, près des eaux, de petites cabanes pour l'abriter. La femelle fait, pour ses œufs un nid d'herbes, et elle les couve pendant six semaines. Le Cygne vit longtemps. Les anciens ont beaucoup vanté le chant qu'il fait entendre, disent-ils, au moment de sa mort. Cependant le cygne domestique est muet, et le cri du cygne sauvage n'a rien d'a- 
172

LE Burrox

gréable. La chair des jeunes cygnes était autrefois fort estimée; on n'en fait plus guère d'usage. Ses plumes s'emploient comme celles des autres palmipèdes. La peau de son ventre sert à faire des fourrures et des houppes. 


\section{DES VARIÉTES}

DE L'ESPÈCE HUMAINE.

Les espèces, chez les hommes, ne sont pas moins variées que chez les animaux : il y en a de petits, il y en a de grands, il a des géants, il y a aussi des nains, et des hommes de toutes les grandeurs entre ces deux extrêmes; il y en a de blancs, de noirs, de mulâtres et des nègres blancs ou albinos. On divise ordinairement les hommes en quatre races principales : $1^{\circ}$ la race caucasique ou européenne. $2^{\circ} \mathrm{La}$ race mongole qui comprend les tartares et les chinois. Les individus de cette race ont le teint jaune, les pommettes des joues saillantes et les yeux obliques c'est-à-dire penchés vers le bas du nez. $3^{n}$ La race amériçaine à peau rougeâtre et saus barbe. $4^{\circ}$ La race nègre à peau noire, à grosses lèvres et à cheveux crépus:

La taille ordinaire des hommes est de $10^{*}$ 
un mètre soixante centimètres à un mètre quatre vingt-dix centimètres; tout ce qui est infiniment au-dessus ou au-dessous de cette hauteur, est un géant ou un nain. Les géants doivent être regardés comme des variétés très-rares, il faut des siècles pour les produire. On a vu à Rouen, en 1735 , un géant de sept pieds deux lignes. La même année à Paris, on en a vu un qui avait six pieds cinq pouces huit lignes. Si de temps à autre il paraît des hommes d'une taille extraordinaire pour la grandeur, il en paraît de même de remarquables par leur petitesse. Parmi les jeux de la nature on le voit quelquefois travailler en miniature avec une justesse admirable de proportions. Le petit Bébé, nain du roi de Pologne, dont on peut voir le squelette au Muséum, en est un exemple. Cet enfant, né d'un père et d'une mère bien constitués, habitant des Vosges, ne pesait qu'un peu plus d'une livre en venant au monde; sa bouche était si petite, qu'elle ne pouvait recevoir le mamelon de sa mère; une chèvre fut sa nourrice. A l'àge de deux 
DES ENFANTS.

ans il commença à marcher, on lui fit des souliers de huit lignes de longueur; à six ans, il était haut de cinq pouces sept lignes. Malgré la bonne éducation que le roi lui fit donner, on ne vit point de talent se développer; toute son intelligence ne passait pas les bornes de l'instinct; jamais on n'a pu lui apprendre à lire. Les passions, cependant, régnèrent dans son âme, il était susceptible de jalousie, de colère et d'emportement. A l'âge de quatorze ans il avait dix pouces neuf lignes de hauteur; c'était son âge brillant; il était joli et bien fait. A quinze ans, au moment où la nature développa ses forces, il devint valétudinaire, ses forces s'affaiblirent, sa tête se pencha, l'épine du dos se courba, il était dans l'état d'un sexagénaire; il perdit sa gâté et périt à g̊vingt-deux ans; la nature chez lui était épuisée. On a vu encore plusieurs nains mourir également jeunes, et paraissant être dans la décrépitude de la vieillesse. 


\section{TABLE ALPHABÉTIQUE.}

\section{A.}

Aigle noir commun. . . . . 151 Alouette. . . . . . . . . . 169 Ane. . . . . . . . . . 5 Anguille. . . . . . . 118

\section{B.}

Basilic. . : . . . . : . . 101 Bec croisé. . . . . . . . 156 C.

Caméléon. . . . . . . 98 Casoar. . . . . . . . . 157 Castor. . . . . . . . . . 73 Cerf. . . . . . . . : 61 Chameau. . . . . : . . 67 Chamois. . . . . . . 23 
TABLE.

177

Chat.

Chardonnerel. . . . . . . 164

Chauve-souris. . . . . . . . 25

Cheval. . . . . . . . . . 1

Chien. . . . . . . . . . 7

Cigogne. . . . . . . . . . 158

Coq-d'Inde.' . . . . . . . . 140

Coq domestique. . . . . . . 142

Couleuvre des dames. . . . . 119

Couleuvre commune. . . . . . 121

Crapaud. . . . . . . . 102

Crocodile. . . . . . . . . 95

Cygne. . . . . . . . 171

\section{D.}

Devin. . : : : . . : : . 109

Duc (le moyen). $\quad . \quad$. . . . 155

E.

Écureuil. . : . : : * . . . 21

Elephant. . . . . . . . . 51

Espadon. . . . . . . . . . 129

Epée de mer. . . . . . . . 130

F.

Fanvelle. . . . . . . . . . 168 
G.

Grenouille commune. . $:$. . 105

H.

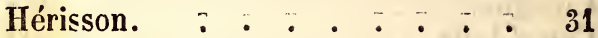

Hirondelle. . . . . . . . . 166

Huppe. . . . . . . . . . 149

I.

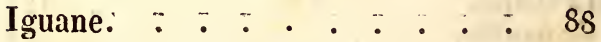

J

Jocko. • : : . . . . : . 77

L.

Léopard. . . . . . . . 49

Lézard vert. • • • • • • . 91

Lézard gris. • . . . . . . 92

Lézard volant. . . . . . . . 137

Lièvre. . . . . . . . . . 58

Lion. • • • . . . . . . 33

Loup. . . . . . . . . . 10

Lynx. . . . . . . . . . . 50

M.

Malbrouck. . . . . . . . . 81

Mangeur de poivre. . . . . 162 
TABLE.

Marmolte. • . . . . . . . 86 Midas. . . . . . . . , . 84 Moineau. . . . . . . . . 165 Moyen Duc. . . . . . . . 154

\section{N.}

Nez ridé. • . . . • . • . 126

Nilgaut. . . . . . . . . 71

0.

Oiseau du paradis. $\quad$. $\quad . \quad . \quad . \quad . \quad 163$ Orang-Outang. . . . . . . : 79

Ours. . . . . . . . . 41 Outarde. . . . . . . . 161

P.

Panthère. : . . . : : : : : 47

Paon. . . . . . . . . 138

Pélican. . . . . . . : . 147

Pigeon. . . . . . . . . 170

Pipe. . . . . . . . : : : 125

Phoque. . , . . . . . . . 132

Poisson-Bonle. . . . . ?. . 128

Poisson-Volant . . . : : : 145

Porc-Epic de mer. • . * 127 


\section{R.}

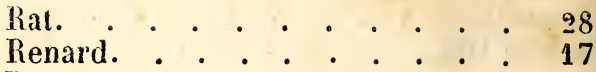

Requin. . . . . . . . 124

Rhinocéros. . . . . . . . . 64

Roitelet. . . . . . . . . 168

Rossignol, . . . . . . . . 167

Rousse. . . . . . . 108

S.

Serpent. . . . . . . . . 113

Souris. . . . . . . . . . 26

\section{$\mathrm{T}$.}

Tigre. . . . . . . . . 45 Tortue géométrique. . . . . $\quad$. 83

$$
\text { V. }
$$

Variétés de l'espèce humaine. . . 172 Vaulour moine. $\quad . \quad$. . . . 152 Vipère. . . . . . . . 115

FiN DE LA TABLE.

Le Hats, Imprimerje de GALLIENNE. - Is4\% 




$$
\text { เ }
$$


穴

SMITHSONIAN INSTITUTION LIBRARIES

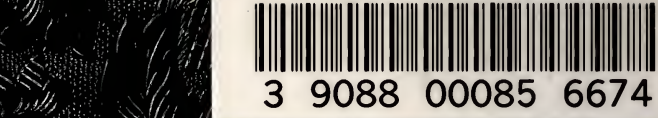

N

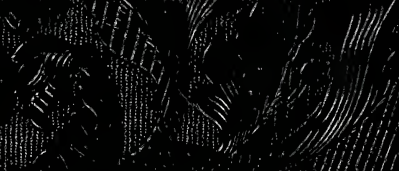

4

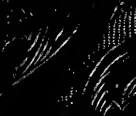

is

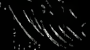

WII.

\section{$\therefore$ is 2} (ii)
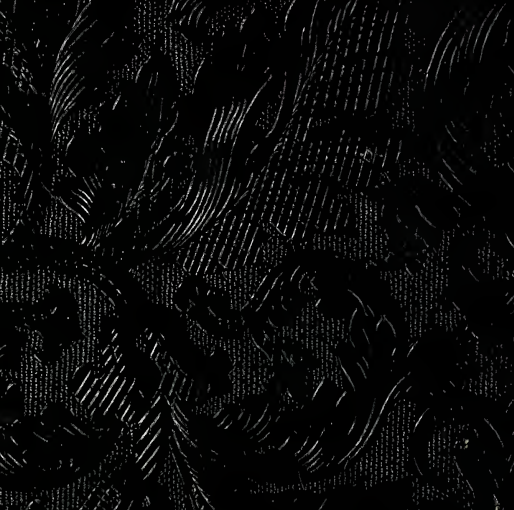